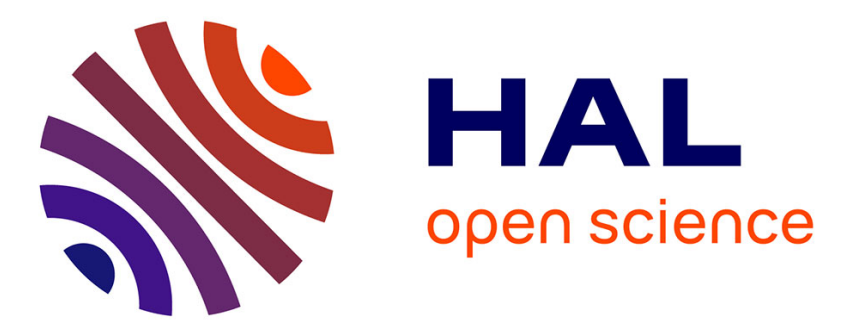

\title{
Dependence of seismic coupling on normal fault style along the Northern Mid-Atlantic Ridge
}

Jean-Arthur Olive, Javier Escartin

\section{To cite this version:}

Jean-Arthur Olive, Javier Escartin. Dependence of seismic coupling on normal fault style along the Northern Mid-Atlantic Ridge. Geochemistry, Geophysics, Geosystems, 2016, 17 (10), pp.4128-4152. 10.1002/2016gc006460 . insu-01875638

\section{HAL Id: insu-01875638 https://hal-insu.archives-ouvertes.fr/insu-01875638}

Submitted on 17 Sep 2018

HAL is a multi-disciplinary open access archive for the deposit and dissemination of scientific research documents, whether they are published or not. The documents may come from teaching and research institutions in France or abroad, or from public or private research centers.
L'archive ouverte pluridisciplinaire HAL, est destinée au dépôt et à la diffusion de documents scientifiques de niveau recherche, publiés ou non, émanant des établissements d'enseignement et de recherche français ou étrangers, des laboratoires publics ou privés. 


\section{Geochemistry, Geophysics, Geosystems}

\section{RESEARCH ARTICLE \\ 10.1002/2016GC006460 \\ Dependence of seismic coupling on normal fault style along the Northern Mid-Atlantic Ridge}

Key Points:

- Greater seismic moment release rates at detachment-bearing sections of the Mid-Atlantic Ridge compared to abyssal hill-bearing sections

- Coupled seismic thickness likely greatest $(\sim 2 \mathrm{~km})$ at individual detachment faults of finite along-axis extent, and averages $\sim 500 \mathrm{~m}$ elsewhere

- Rate and state friction theory attributes differences in seismic coupling to the thermo-mechanical state and lithology of oceanic normal faults

Supporting Information:

- Supporting Information S1

- Data Set S1

- Data Set S2

- Data Set S3

- Data Set S4

- Data Set S5

- Data Set S6

Correspondence to:

J.-A. Olive,

jaolive@Ideo.columbia.edu

Citation:

Olive, J.-A., and J. Escartín (2016),

Dependence of seismic coupling on normal fault style along the Northern Mid-Atlantic Ridge, Geochem. Geophys. Geosyst., 17, 4128-4152, doi:10.1002/ 2016GC006460.

Received 27 MAY 2016 Accepted 6 SEP 2016 Accepted article online 10 SEP 2016 Published online 27 OCT 2016

\author{
Jean-Arthur Olive ${ }^{1}$ and Javier Escartín ${ }^{2}$ \\ ${ }^{1}$ Lamont-Doherty Earth Observatory, Columbia University, Palisades, New York, USA, ${ }^{2} \mathrm{CNRS} /$ Institut de Physique du Globe \\ de Paris, Paris, France
}

\begin{abstract}
While normal faults are essential in shaping the seafloor formed at slow spreading mid-ocean ridges, information on their behavior on short (seismic cycle) time scales is limited. Here we combine catalogs of hydro-acoustically and teleseismically recorded earthquakes to characterize the state of seismic coupling along the Northern Mid-Atlantic Ridge (MAR) between $12^{\circ} \mathrm{N}$ and $35^{\circ} \mathrm{N}$. Along this portion of the MAR axis, tectonic extension is either taken up by steep conjugate faults that outline well-defined ridge-parallel abyssal hills, or dominantly by a large-offset detachment fault on one side of the axis. We investigate variations in seismicity and seismic moment release rates across 30 ridge sections that can be clearly characterized either as abyssal hill or detachment bearing. We find that detachment-bearing sections are associated with significantly greater seismicity and moment release rates than abyssal hill-bearing sections but show variability that may reflect the along-axis extent of individual detachment faults. Overall, the measured seismic moment release rates fail to account for the long-term fault slip rates. This apparent seismic deficit could indicate a mixed-mode of fault slip where earthquakes only account for $\sim 10-30 \%$ of offset buildup at abyssal hill faults, while the rest is accommodated by some form of transient aseismic creep. We find this seismic coupling fraction to be significantly greater ( 40-60\%) at individual detachment systems, which is somewhat at odds with the common inference that detachment faults can sustain long-lived localized strain because they are weak. We therefore propose alternative interpretations for seismic coupling based on dynamic friction theory.
\end{abstract}

\section{Introduction}

The formation of new oceanic lithosphere at mid-ocean ridges involves a complex interplay of tectonic and magmatic processes. On geological time scales, a sizeable fraction of the extensional strain at the ridge axis is taken up by the magmatic emplacement of new oceanic crust and lithosphere, while the remaining fraction is accommodated by slip on lithosphere-scale normal faults [MacDonald et al., 1996; Escartín et al., 1999; Buck et al., 2005]. Both processes contribute to shaping the morphology of abyssal hills, the most prominent landform on the Earth's surface. However, the manifestation of these processes on short time scales ( $<100$ years) remains poorly understood. While the quantum event of magmatic accretion can consist of a melt lens replenishment episode [e.g., Wilcock et al., 2009], a dike intrusion event [e.g., Tolstoy et al., 2001; Dziak et al., 2004], or eruption of lava on the seafloor [e.g., Haymon et al., 1993], it is unclear whether the accumulation of slip on mid-ocean ridge normal faults results from a succession of earthquakes, from transient aseismic creep, or a combination of both. Further, determining whether the nature of this quantum tectonic event varies with spreading rate, seafloor morphology, or locally with styles of normal faulting has important implications for ridge dynamics [Cowie et al., 1993].

The seismogenic properties of mid-ocean ridges have received significant attention over the last few decades. Studies of teleseismic waveforms have established that large normal faulting earthquakes (magnitude 5-6) typically occur on $\sim 45^{\circ}$ dipping faults and can nucleate at depths of 6-7 km or more at slow spreading ridges [Huang et al., 1986; Huang and Solomon, 1988]. By contrast, scarce seismic ruptures appear confined to the uppermost $\sim 2-3 \mathrm{~km}$ of the crust at intermediate and fast ridges. Solomon et al. [1988] calculated the total energy released by earthquakes on slow spreading ridges and argued that it could only account for $10-20 \%$ of the total plate separation rate. Cowie et al. [1993] later argued that seismic slip had to represent an insignificant fraction $(<1 \%)$ of the time-averaged fault slip rate at the fast spreading East Pacific Rise. 
Subsequent studies documented an exponential decrease in seismic moment release rates, and thus seismically accommodated strain, between slow and fast spreading centers [Sobolev and Rundquist, 1999; Rundquist and Sobolev, 2002; Bird et al., 2002; Frohlich and Wetzel, 2007].

A commonly accepted interpretation for this trend is that it reflects the warmer thermal structure of faster spreading ridges, which potentially reduces the area of the fault where seismic slip can occur [Cowie et al., 1993; Rundquist and Sobolev, 2002]. In this scenario, the limited contribution of coseismic displacements to long-term fault slip reflects the limited spatial extent of seismic ruptures relative to the total fault surface. Whether this hypothesis holds at fast spreading rates, where normal faulting earthquakes as large as $M_{w} \sim$ 5.4 [Bird et al., 2002] and microearthquakes down to depths of 2-3 km [Wilcock et al., 1992] have been documented, is an open question. Cowie et al. [1993] also pointed out that the decrease in seismic moment release rate with spreading rate could partially reflect an increase in magmatically accommodated strain. In other words, the time-averaged slip rate of faults (seismic + aseismic) at faster spreading ridges may be a lesser fraction of the total plate separation rate, which integrates seismic fault slip, aseismic fault slip, and magmatic emplacement [Buck et al., 2005; Behn and Ito, 2008; Olive et al., 2015]. This would reduce the contribution of seismic slip alone to the total plate separation, and result in apparently lower seismic coupling coefficients at faster rates that are not directly related to fault properties but instead to the more robust magma supply.

In order to move this debate forward and to better understand strain partitioning at ridges where magmatic processes are not dominant, we follow an alternative approach. We propose an assessment of the variability in seismically accommodated fault slip within a single slow spreading ridge section where the extension rate is fixed, but that shows along-axis variations in seafloor morphology commonly interpreted as variations in magma supply and axial thermal regime. On the Northern Mid-Atlantic Ridge (MAR), over 50\% of the seafloor is presently formed within sections characterized by a well-defined axial valley flanked by axisfacing normal faults regularly spaced by $\sim 5-10 \mathrm{~km}$ (Figure $1 \mathrm{~A}$ ). These faults outline elongated abyssal hills that are continuous along-axis and roughly symmetric about the neovolcanic zone (Figure 1B). In the following, we refer to this type of ridge section as abyssal hill bearing, or $A B$ section. By contrast, the remainder of the Mid-Atlantic seafloor is currently formed within sections that have a much more asymmetric morphology [Escartín et al., 2008a], as most of the tectonic strain is locally accommodated along large-offset faults, including oceanic detachments, located on one side of the axis (Figure 1C). These sections are hereafter termed detachment bearing, or DB sections.

Over the last decade or so, multiple studies of seafloor geology, geochemistry, geophysics as well as geodynamic modeling have led to an emerging paradigm where the occurrence of these two end-member modes of seafloor formation reflects along-axis heterogeneities in the amount of melt supplied to the axial lithosphere. Specifically, AB sections may receive enough melt influx to take up most of the plate separation, especially at the center of first and second-order segments [Kuo and Forsyth, 1988; Tucholke and Lin, 1994]. The sustained emplacement of new oceanic crust continuously pushes active normal faults away from the axis where it becomes difficult to sustain their growth [Buck et al., 2005; Behn and Ito, 2008; Olive et al., 2015]. Rapid rates of magma intrusion thus promote the formation of multiple short-lived (up to $\sim 1 \mathrm{~km}$ offset) normal faults. On the other hand, DB sections, whether they make up the ends of dominantly $A B$ segments (e.g., at ridge-transform intersections) or an entire segment (e.g., section 1 in Figure 1A) likely receive a lesser melt influx relative to their axial lithospheric thickness [Tucholke et al., 2008]. This could be due to underlying mantle heterogeneities locally suppressing melt production [Escartín et al., 2008a; Wilson et al., 2013], or to a large portion of the produced melt remaining stuck at depth and never intruding the lithosphere [Cannat, 1996; Olive et al., 2010]. This reduced melt influx contributes to shaping a thicker, stronger axial lithosphere in which actively slipping faults do not migrate off-axis quite as fast as in AB sections, and are thus more likely to accumulate large offsets, eventually becoming mature detachments [Buck et al., 2005; Tucholke et al., 2008; MacLeod et al., 2009; Olive et al., 2010]. This paradigm, however, makes no clear prediction regarding the slip behavior of these different types of faults on seismic cycle time scales.

Recent improvements in the instrumentation of the MAR have enabled a detailed characterization of seismicity in each type of section with both ocean bottom seismometers (OBS) and hydrophone arrays. OBS studies illuminate a deeper seismogenic layer (microearthquakes occur down to depths of $\sim 7-8 \mathrm{~km}$ ) at DB sections compared to $A B$ sections ( 5-6 km) [Toomey et al., 1988; Kong et al., 1992; Wolfe et al., 1995; Barclay et al., 2001; DeMartin et al., 2007; Crawford et al., 2013; Grevemeyer et al., 2013]. Further, the Mid- 


\section{QAGU Geochemistry, Geophysics, Geosystems}

A.

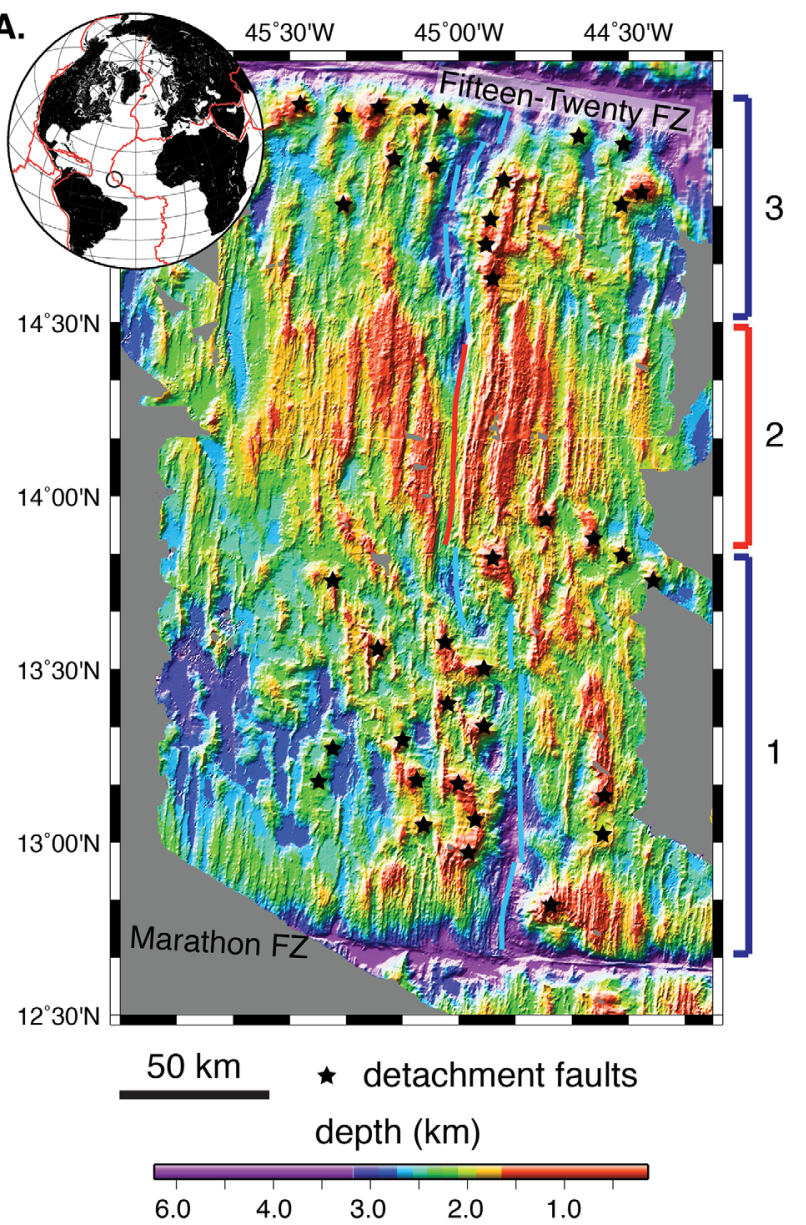

B. Abyssal hill-bearing section
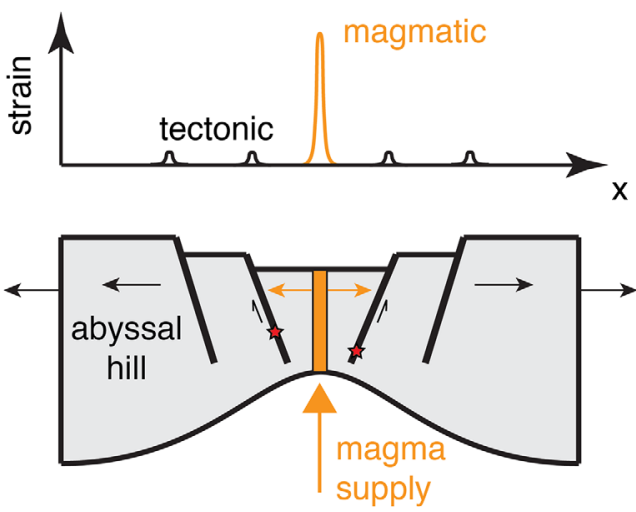

C. Detachment-bearing section

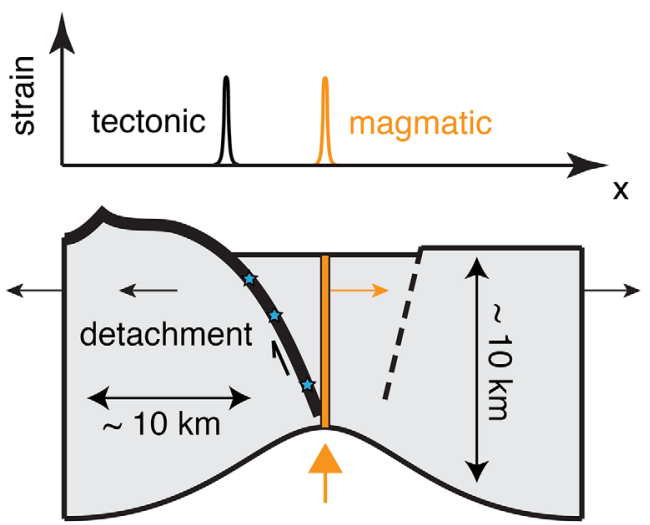

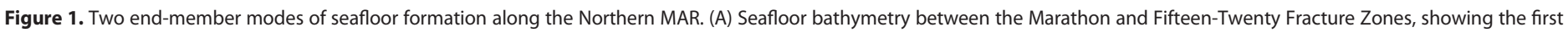
three sections listed in Table 1. Blue and red curves indicate the ridge axis at detachment bearing (DB) and abyssal hill bearing (AB) sections, respectively. Black stars mark individual

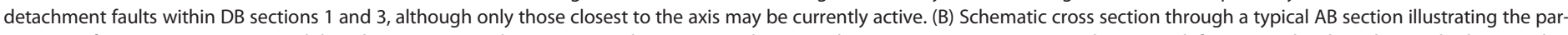
titioning of strain in young oceanic lithosphere (gray area) between crustal accretion in the neo-volcanic zone (orange curve) and tectonic deformation distributed on multiple normal

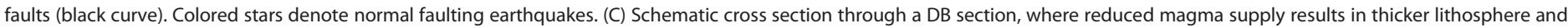
more localized tectonic strain.

Atlantic hydrophone array, which has a magnitude detection threshold as low as $\sim 3$ [Bohnenstiehl et al., 2000, 2002; Smith et al., 2003], revealed higher seismicity rates (number of events per unit time per unit length along-axis) at DB sections relative to AB sections [Escartín et al., 2008a]. Simão et al. [2010] later found systematic differences in the seismicity rates and duration of major mainshock-aftershock sequences between the two types of ridge sections, which they interpreted as reflecting the inferred weakness of detachment fault zones.

To date, however, no study has attempted a systematic characterization of seismically accommodated fault slip at the scale of individual $\sim 100 \mathrm{~km}$ long ridge sections. This is largely because (1) teleseismic catalogs have large location uncertainties, (2) OBS deployments are scarce and limited spatially, and cover time periods too short to yield reliable estimates of seismic moment release; and (3) hydro-acoustic catalogs do not provide a straightforward measure of earthquake magnitude. We propose to circumvent these difficulties by using the 4 year long hydro-acoustic catalog of seismicity along the Northern MAR [Bohnenstiehl et al., 2002; Smith et al., 2003], and developing a method to estimate relative variations in seismic moment release rates across sections. Then, using representative regional averages of moment release on a $\sim 40$ year period from a teleseismic catalog, we transform our relative measurements into absolute estimates of seismic moment release rates along the ridge. Those are expressed as coupled thicknesses [e.g., Bird et al., 2002], which are then interpreted in terms of the seismic coupling coefficient that best characterizes $A B$ and $D B$ sections. Our analysis suggests that detachment faults are associated with the greatest degree of seismic 


\section{QAGU Geochemistry, Geophysics, Geosystems}
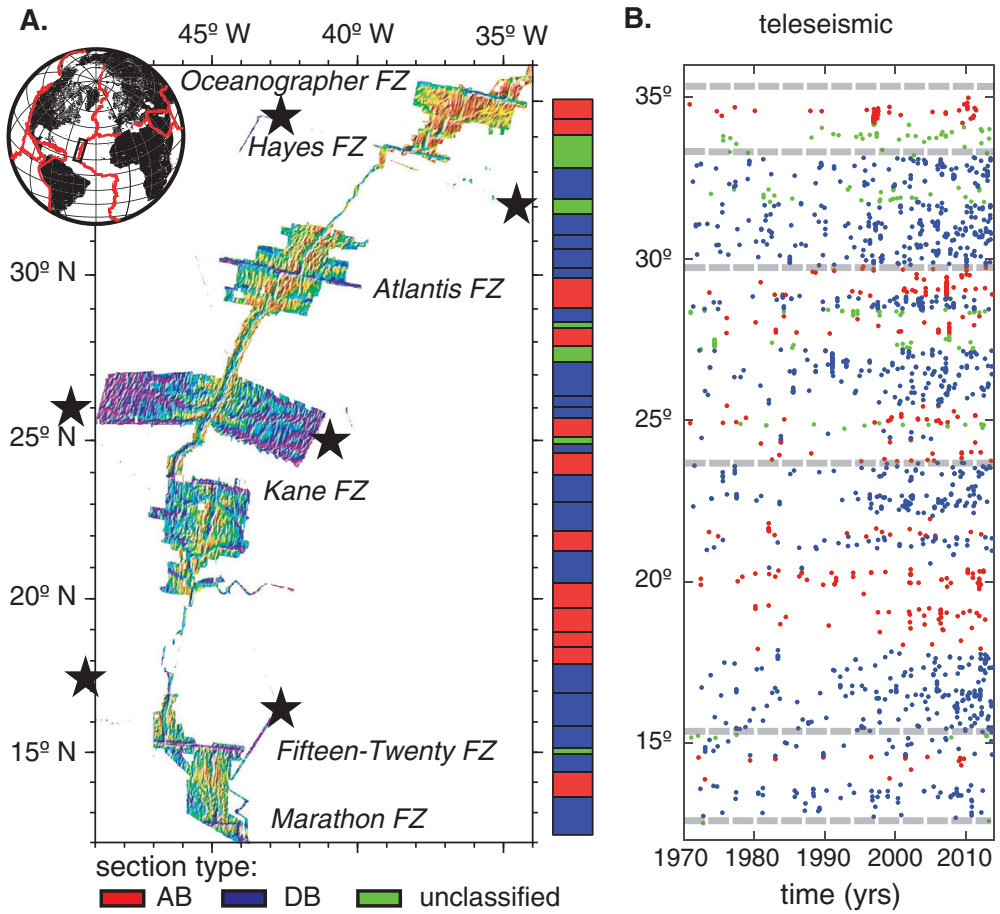

C.

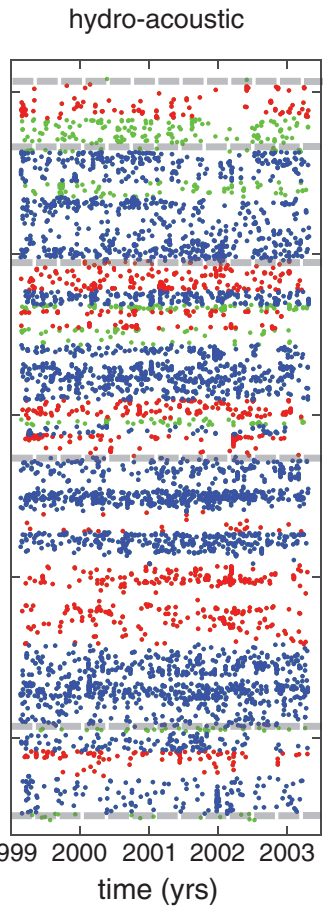

D.

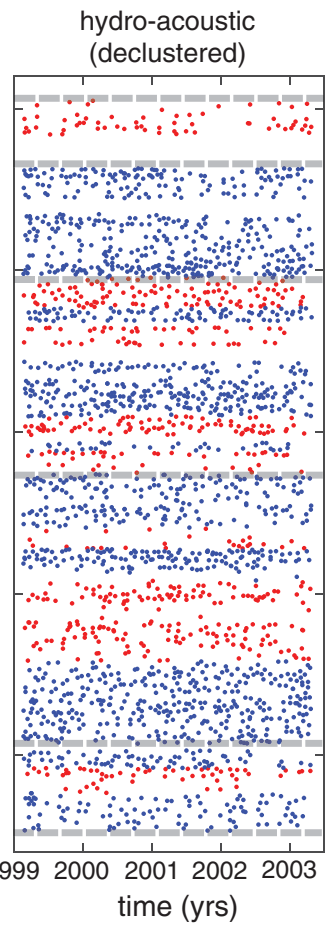

Figure 2. Earthquake catalogs analyzed in this study. (A) Map of the study area indicating the location of the hydrophones that recorded the hydro-acoustic catalog (stars). The vertical colored bar shows the distribution of ridge sections listed in Table 1. Red, blue, and green refer to AB sections, DB sections, and unclassified sections, respectively. (B) Latitude of earthquakes from the ISC teleseismic catalog plotted versus time since 1 January 1999. Red and blue events occurred on AB and DB sections, respectively, while green events occurred on unclassified sections. (C) Hydro-acoustically recorded earthquakes between 1999 and 2004 [Smith et al., 2003]. (D) Hydro-acoustic catalog following a declustering analysis where earthquakes occurring within 13 ST-days-km of each other were collapsed into a single event (see section 4.2 for details). Dashed gray lines mark the location of transform faults.

coupling, which may seem somewhat counter-intuitive if they are indeed weak from a static friction perspective. We thus use arguments from the theory of dynamic (rate and state) friction to discuss how our observations could directly reflect the colder thermal regime expected at detachment faults, or a specific pattern of lithological heterogeneities within detachment fault zones.

\section{Study Area: The Northern Mid-Atlantic Ridge $\left(12^{\circ} \mathrm{N}-36^{\circ} \mathrm{N}\right)$}

The MAR is a slow spreading mid-ocean ridge $(2.5 \mathrm{~cm} / \mathrm{yr}$ full rate) characterized by a $\sim 10-20 \mathrm{~km}$ wide axial valley bordered by normal faults and segmented by transform and nontransform offsets [e.g., Searle and Laughton, 1977; Spencer et al., 1997]. We focus here on the seismogenic behavior of the Northern MAR between the Marathon Fracture zone at $12^{\circ} \mathrm{N}$ and the Oceanographer Fracture Zone at $36^{\circ} \mathrm{N}$ (Figure $2 \mathrm{~A}$ ). This $2600 \mathrm{~km}$ long boundary between the African and North American plates has been the focus of extensive geophysical and geological studies [e.g., Cannat et al., 1995; Tucholke et al., 1997; Bohnenstiehl et al., 2002; Smith et al., 2003, 2006; Simão et al., 2010], and variations in the mode of seafloor accretion along this portion of the ridge axis have been systematically characterized [Escartín et al., 2008a].

To facilitate a systematic analysis of ridge seismicity in relation to mode of seafloor spreading, we divide the study area into 30 ridge sections averaging $70 \mathrm{~km}$ in length. Section boundaries are chosen to coincide with transform faults, nontransform offsets, or sharp changes in ridge valley flank morphology when a nontransform offset cannot be clearly established. We avoided defining sections shorter than $30 \mathrm{~km}$ to ensure that earthquakes can be reliably assigned to a given section even if their location uncertainty averages $\sim 10 \mathrm{~km}$. On the other hand, we also avoided defining sections longer than $130 \mathrm{~km}$ in order to retain a consistent along-axis resolution. Sections are then categorized as $A B$ or $D B$ following the classification of Escartín et al. [2008a] (Figure 1). A few sections between $12^{\circ} \mathrm{N}$ and $36^{\circ} \mathrm{N}$ cannot be unequivocally classified and were thus excluded from the subsequent analysis. This leaves $\sim 2200 \mathrm{~km}$ of ridge axis binned into 12 $A B$ sections (39\% of the axial length) and 18 DB sections (the remaining 61\%). The resulting ridge partitioning is shown in Figure 2 and summarized in Table 1. 


\begin{tabular}{|c|c|c|c|c|c|}
\hline $\begin{array}{l}\text { Section } \\
\text { Number }\end{array}$ & $\begin{array}{l}\text { Section } \\
\text { Type }\end{array}$ & $\begin{array}{l}\text { Southern End } \\
\text { (Latitude, }{ }^{\circ} \mathrm{N} \text { ) }\end{array}$ & $\begin{array}{l}\text { Northern End } \\
\text { (Latitude, }{ }^{\circ} \mathrm{N} \text { ) }\end{array}$ & $\begin{array}{c}\text { Section } \\
\text { Length }(\mathrm{km})\end{array}$ & $\begin{array}{c}\text { Tectonic } \\
\text { Fraction }(T)\end{array}$ \\
\hline 1 & DB & 12.6626 & 13.835 & 129.7847 & \\
\hline 2 & $A B$ & 13.835 & 14.6036 & 85.084 & $0.38 \pm 0.1^{b}$ \\
\hline 3 & DB & 14.6036 & 15.1645 & 62.0916 & \\
\hline 4 & DB & 15.3333 & 15.9 & 62.7337 & \\
\hline 5 & DB & 15.9 & 16.95 & 116.235 & \\
\hline 6 & DB & 16.95 & 17.9131 & 106.6152 & \\
\hline 7 & $A B$ & 17.9131 & 18.5 & 64.9698 & \\
\hline 8 & $A B$ & 18.5 & 18.95 & 49.815 & \\
\hline 9 & $A B$ & 18.95 & 19.75 & 88.56 & \\
\hline 10 & $A B$ & 19.75 & 20.4061 & 72.6303 & $0.3 \pm 0.1^{b}$ \\
\hline 11 & DB & 20.4061 & 21.3928 & 109.2277 & \\
\hline 12 & $A B$ & 21.3928 & 22.0197 & 69.3978 & $0.35 \pm 0.1^{b}$ \\
\hline 13 & DB & 22.0197 & 23.05 & 114.0542 & \\
\hline 14 & DB & 23.05 & 23.7176 & 73.9033 & \\
\hline 15 & $A B$ & 23.7176 & 24.4034 & 75.9181 & $0.41 \pm 0.1^{b}$ \\
\hline 16 & DB & 24.4034 & 24.6807 & 30.6971 & \\
\hline 17 & $A B$ & 24.9097 & 25.4763 & 62.7226 & $0.35 \pm 0.1^{b}$ \\
\hline 18 & DB & 25.4763 & 25.97 & 54.6526 & \\
\hline 19 & DB & 25.97 & 26.33 & 39.852 & \\
\hline 20 & DB & 26.33 & 27.1865 & 94.8146 & \\
\hline 21 & $A B$ & 27.6792 & 28.2338 & 61.3942 & $0.36 \pm 0.1^{b}$ \\
\hline 22 & DB & 28.4266 & 28.8486 & 46.7154 & \\
\hline 23 & $A B$ & 28.8486 & 29.7754 & 102.5968 & $0.29 \pm 0.08$ \\
\hline 24 & DB & 29.7754 & 30.0888 & 34.6934 & \\
\hline 25 & DB & 30.0888 & 30.8 & 78.7298 & \\
\hline 26 & DB & 30.8 & 31.25 & 49.815 & \\
\hline 27 & DB & 31.25 & 31.7542 & 55.8149 & \\
\hline 28 & DB & 32.2237 & 33.154 & 102.9842 & \\
\hline 29 & $A B$ & 34.1918 & 34.5 & 34.1177 & \\
\hline 30 & $A B$ & 34.5 & 35.2791 & 86.2464 & $0.24 \pm 0.1^{b}$ \\
\hline Total & $A B$ & & & 853 & \\
\hline Total & $A B$ & & & 1363 & \\
\hline Total & $A B$ and $D B$ & & & 2216 & \\
\hline
\end{tabular}

\section{Regional Earthquake Statistics From the 43 Year Long Teleseismic Catalog}

\subsection{Data Set}

We assembled a catalog of teleseismically recorded earthquakes of the Northern Mid-Atlantic Ridge using the reviewed ISC Catalog [International Seismological Centre, 2013] over the time period 1970-2013. We use body wave magnitudes $\left(m_{b(I S C)}\right)$ for all earthquake in our study area, which we converted to moment magnitudes $\left(M_{w}\right)$ using the empirical relation proposed by Das et al. [2011] on the basis of correlations across global catalogs (including ISC). For body wave magnitudes, the conversion formula writes

$$
M_{w}=1.5385 m_{b(I S C)}-2.5385 \text {. }
$$

Equation (1) is valid for $m_{b(I S C)}$ ranging between 2.9 and 6.5, which encompasses our entire catalog. After conversion, our teleseismic data set comprises moment magnitudes between 2.5 and 6.5, with a mean of 4.1. These moment magnitudes are converted to seismic moments $M_{0}$ (in Joules) following:

$$
\log _{10}\left(M_{0}\right)=\frac{3}{2}\left(M_{w}+6.033\right)
$$

In order to assess a characteristic location uncertainty for the events contained in the reviewed ISC catalog, we turned to the ISC-GEM catalog, a global data set of larger events (complete for $M_{w} \geq 6.4$ ), which includes error ellipses for each epicenter location [Storchak et al., 2013]. The semimajor axis length of the error ellipse ( $90 \%$ confidence) averages $9.9 \mathrm{~km}$ among the ISC-GEM earthquakes from our study area and is shorter than $15 \mathrm{~km}$ for $\sim 92 \%$ of the events. A conservative estimate for the location uncertainty of the ISC catalog (which contains smaller events presumably more difficult to locate) is therefore to assume that its true epicenters 
are normally distributed around the reported epicenters with a 2- $\sigma$ uncertainty of $15 \mathrm{~km}$ (i.e., the true epicenter has a $\sim 95 \%$ chance of lying within $15 \mathrm{~km}$ of the reported epicenter). We will use this assumption to propagate location uncertainties for the remainder of our teleseismic catalog analysis. Specifically, we will perform our analysis on 1000 randomly and independently drawn event locations and report the distribution of various observables of interest.

Once epicenter locations are assigned, we select events occurring between 1970 and 2013 within the ridge sections given in Table 1. Each earthquake located within $30 \mathrm{~km}$ of the ridge axis is then classified according to the type of ridge section it occurred on. Our selection criteria are designed to exclude seismicity associated with major transform and nontransform offsets and retain earthquakes related to ridge crest processes. In the absence of focal mechanisms, we must rely on the lack of apparent clustering near transform offsets (Figure 2) to ensure that we have successfully excluded most events that are likely strike slip from the catalog. On average, our teleseismic catalog contains 356 events in AB sections and 1109 events in DB sections. This limited number-an average of $\sim 49$ events per section-precludes detailed analyses of seismicity patterns at the scale of individual sections. We therefore restrict our analysis of the teleseismic catalog so as to determine earthquake statistics from all concatenated $A B$ and $D B$ sections.

\subsection{Gutenberg-Richter Distributions}

We begin by assessing the frequency-size distribution of teleseismic earthquakes according to the type of section they occurred on. We assume that earthquakes follow a Gutenberg-Richter distribution of generic form:

$$
\log _{10}\left(N_{\geq M_{0}}\right)=A-\beta \log _{10}\left(M_{0}\right),
$$

where $N_{\geq M_{0}}$ is the frequency of earthquakes greater than a given moment, $A$ is a parameter related to the seismicity rate, and $\beta$ is the slope of the distribution. Note that some studies formulate equation (3) as a function of moment magnitude and report $b$-values, which are simply $b=3 \beta / 2$ (from equation (2)). The $\beta$-value can be estimated through a maximum likelihood method [Aki, 1965]

$$
\beta=\frac{\log _{10}(e)}{\left\langle\log _{10}\left(M_{0}\right)\right\rangle-\min \left(\log _{10}\left(M_{0}\right)\right)} .
$$

In equation (4), $M_{0}$ denotes the population of seismic moments greater than a moment of completeness $M_{T}$, and brackets indicate the algebraic mean. We estimate $M_{T}$ using the method of Wiemer and Wyss [2000], which consists of assuming increasing (trial) values of $M_{T}$ and determining the corresponding $(A, \beta)$ with a maximum likelihood approach, using 20 bins of $\log _{10}\left(M_{0}\right)$ between the minimum and maximum moment. We then assess the goodness of fit of synthetic Gutenberg-Richter distributions generated from the $(A, \beta)$ pair assigned to each trial $M_{T}$. Finally, the lowest trial $M_{T}$ that can explain $\geq 90 \%$ (or the maximum fraction) of the data variability is retained as the true moment of completeness, and used for the final determination of $(A, \beta)$. Visual inspection of our catalog however reveals a drop in the moment of completeness after $\sim 1992$, possibly resulting from changes in instrumentation or coverage of the study area. We therefore retain pre-1992 $M_{T}$ as the moment of completeness of the entire catalog. This value corresponds to a magnitude of completeness $M_{w T}=4.6$.

We retain earthquakes greater than this size threshold to calculate a seismicity rate $E$ (number of events per unit time, per unit length along-axis), and estimate the Gutenberg-Richter parameters that best fit the observed distribution. This is done for each of the 1000 random drawings of epicenter locations described in section 3.1, yielding distributions of seismicity rates and $\beta$-values that are reported in Figure 3 . Analysis of the entire catalog yields an average seismicity rate of 42 events per century per $100 \mathrm{~km}$ along axis (Figure $3 A$ ). This rate falls between those estimated from all concatenated AB and DB sections ( 26 and 52 events per century per $100 \mathrm{~km}$ along-axis, respectively, Figures $3 \mathrm{~B}$ and $3 \mathrm{C}$ ). The $\beta$-value found for the entire catalog is 0.78 ( \pm 1 standard deviation $=0.01$, Figures $3 \mathrm{D}$ and $4 \mathrm{~A}$ ), which is relatively high with respect to global averages, and in good agreement with typical values from catalogs of normal faulting earthquakes $(\sim 0.73)$ [Schorlemmer et al., 2005]. DB sections have a similar $\beta$-value $(0.75 \pm 0.01$, Figure 3F). By contrast, analysis of all $A B$ sections yields $\beta=0.89 \pm 0.01$ (Figure $3 \mathrm{E}$ ), although an apparent gap in the data set between $M_{w}=5.6$ and 6.4 (Figure $4 \mathrm{~A}$ ) may render this estimate somewhat less reliable and contribute to its large spread. 
Seismicity rate $\left(10^{-3}\right.$ events $\left./ \mathrm{km} / \mathrm{yr}\right)$
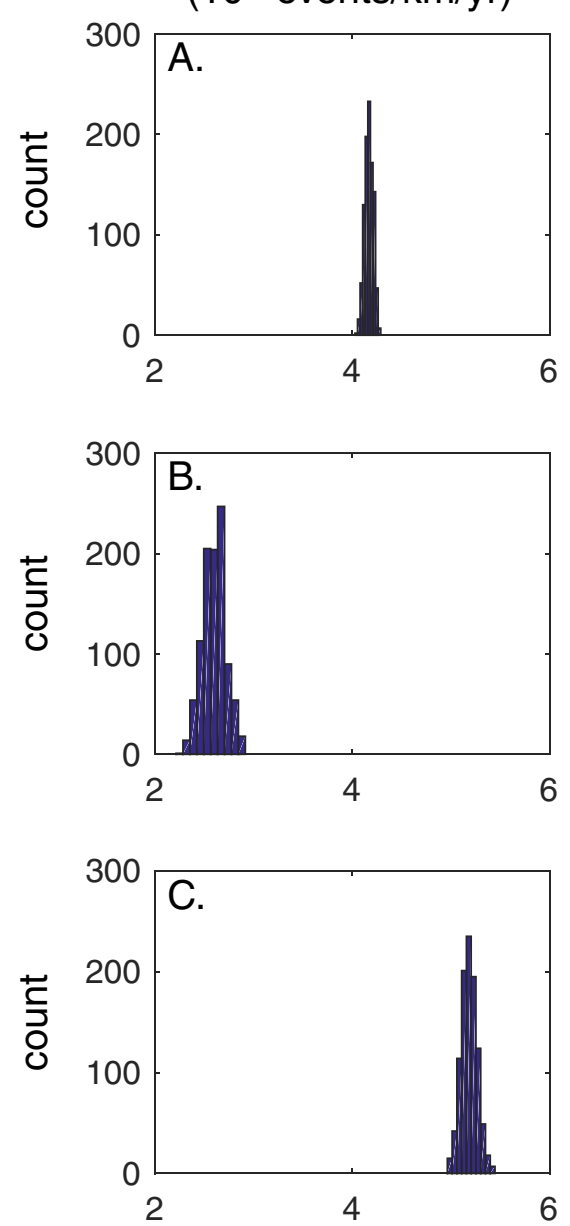

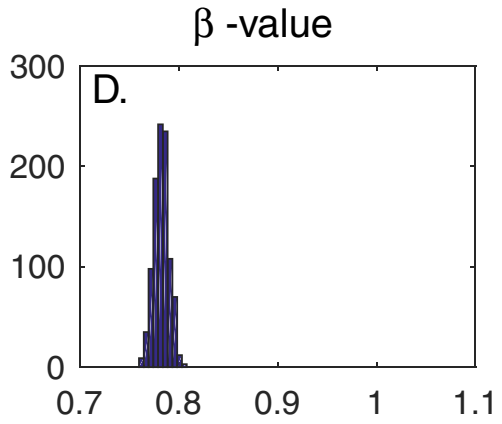

Moment release rate $\left(10^{15} \mathrm{~J} / \mathrm{yr} / \mathrm{km}\right)$
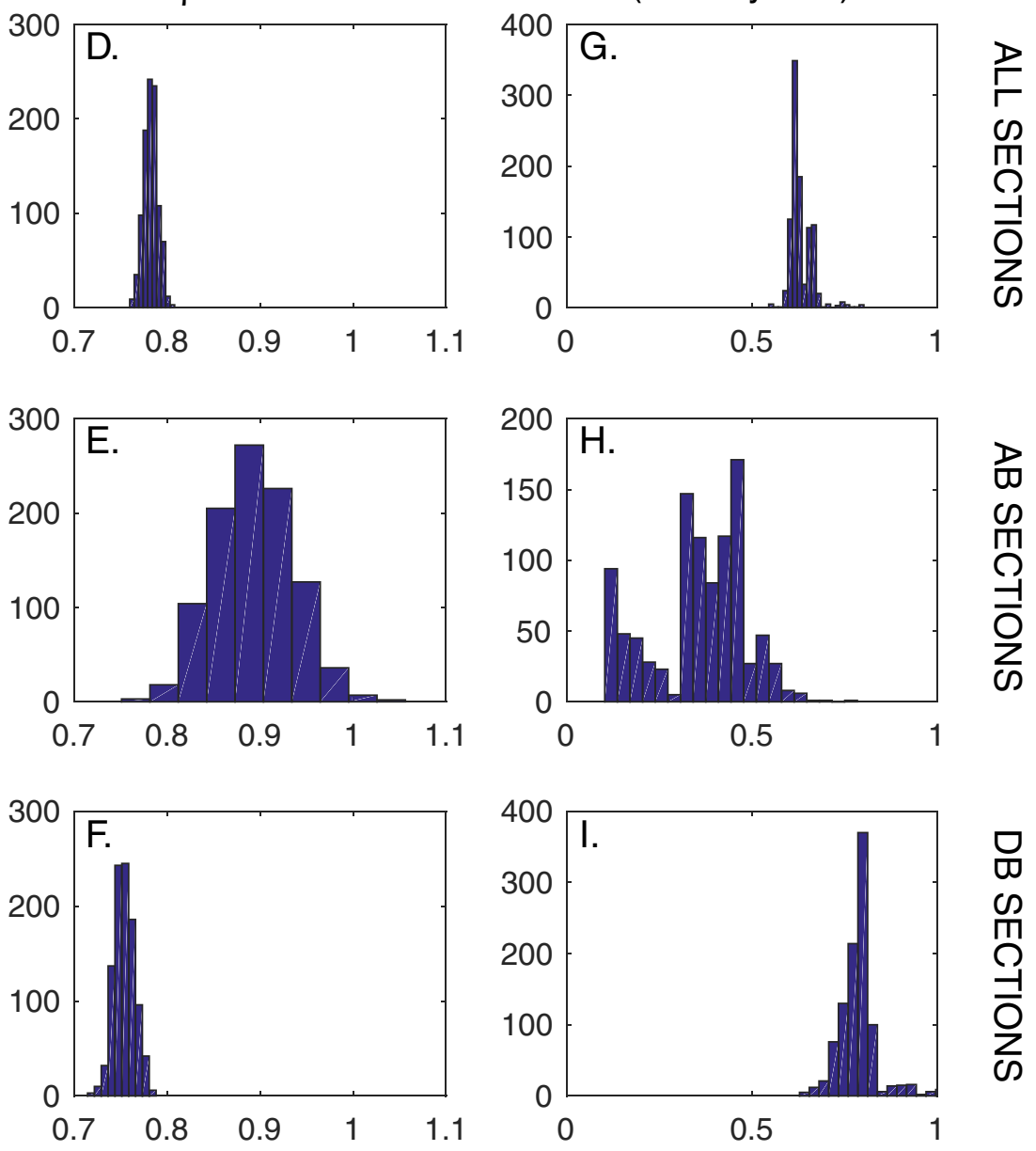

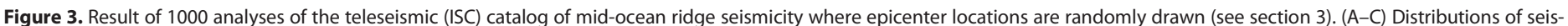
micity rates within $(A)$ the entire study area, $(B)$ all concatenated $A B$ sections, and (C) all concatenated DB sections. (D-F) Same for $\beta$-values of the Gutenberg-Richter distribution. (G-I) Same for the rate of seismic moment release.

\subsection{Moment Release Rates}

We next analyze the teleseismic catalog to evaluate the average rate of seismic energy released over time, $R$, in Joules per year per km along-axis. This quantity can be used as a proxy for seismic coupling, i.e., a measure of seismically accommodated strain along the ridge [Solomon et al., 1988; Cowie et al., 1993]. The most straightforward way to evaluate $R$ is to sum the moments of all earthquakes in the catalog (Figure 5A). We name this estimate $R_{\Sigma}$, and define it as

$$
R_{\Sigma}=\frac{1}{T} \sum_{i} M_{0}(i)
$$

where the sum over $i$ incorporates all events greater than the completeness moment $M_{T}$, and $T$ is the time spanned by the catalog. This estimate of the moment release rate, however, may not always be representative of a true long-term average. Indeed, in Gutenberg-Richter distributed earthquake populations, the largest (and therefore rarest) events account for the majority of the cumulated moment release. Yet the time frame of earthquake catalogs is often too short to record enough large events to properly constrain their contribution to the overall energy release. To remedy this bias, Frohlich [2007] proposed alternative estimates that make use of the parameters of the Gutenberg-Richter distribution. Here we use estimates based on moment rankings $R_{k}$, which are defined as 


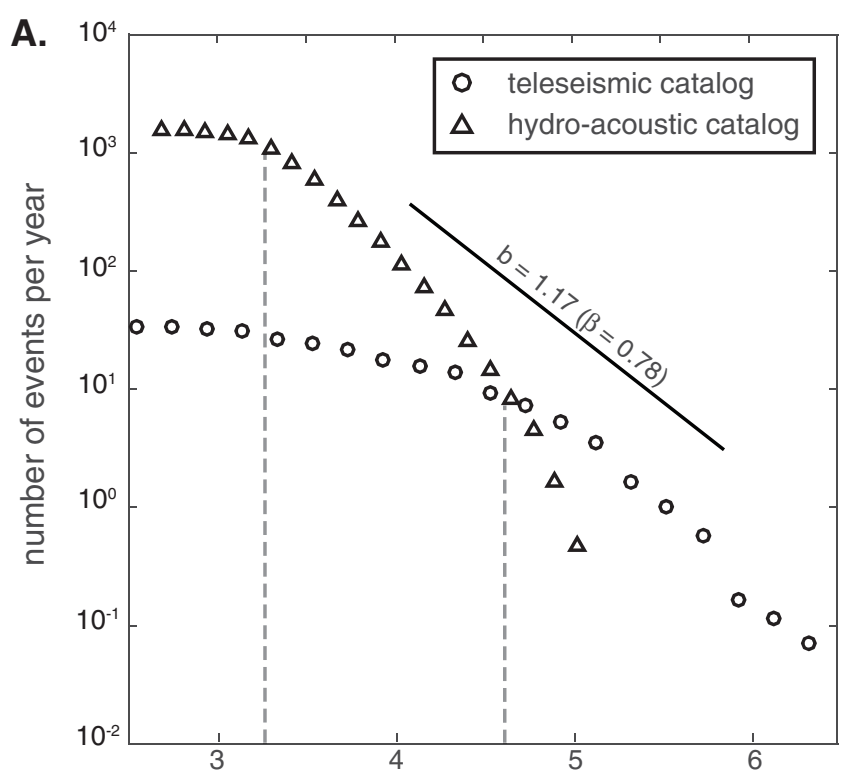

B.

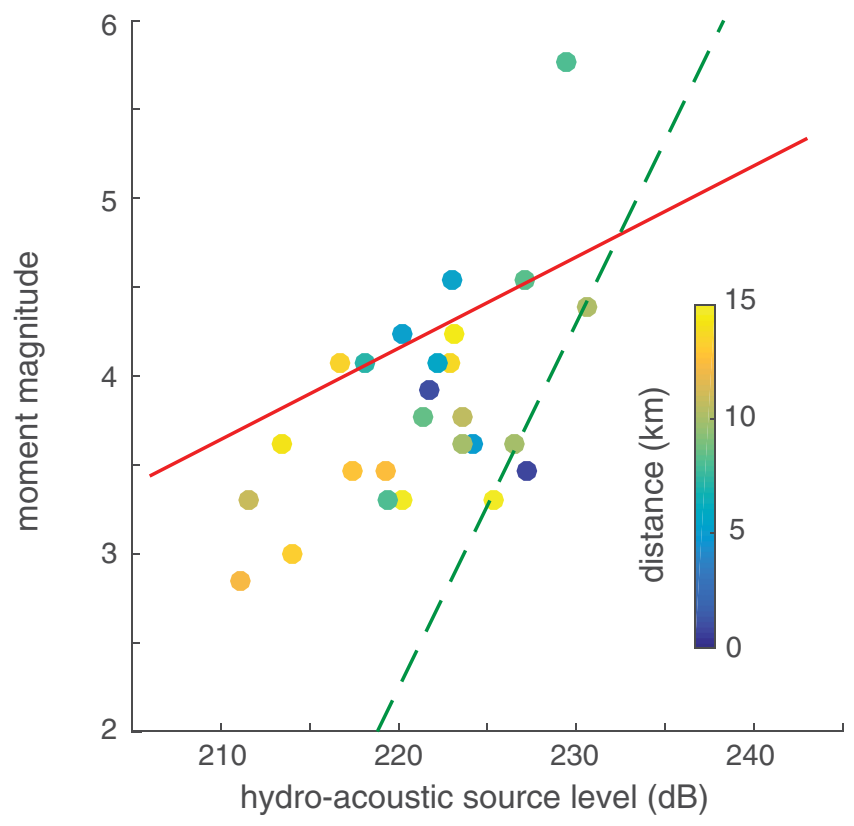

Figure 4. (A) Frequency-size distribution of the entire teleseismic catalog (circles), and slope of the best-fitting Gutenberg-Richter law (line), determined from a maximum likelihood approach (see section 3.2). The frequency-size distribution of the hydro-acoustic catalog (triangles) is plotted assuming a simple mapping between seismic moment $\left(M_{0}\right)$ and hydro-acoustic source level $(S)$ that yields it the same $\beta$-value as the teleseismic distribution (see section 4.3). Vertical dashed lines indicate the magnitude of completeness for the hydro-acoustic and teleseismic catalogs. (B) Moment magnitude and source level of events identified in both teleseismic and hydro-acoustic catalogs (see section 4.3). Events are color-coded by the distance between their estimated locations in each catalog. The red line is our assumed mapping, and the green dashed line is the regression-based mapping of Pan and Dziewonski [2005].

$$
R_{k}=\frac{\beta}{(1-\beta)} \frac{M_{0}^{(k)}}{T} k^{\frac{1}{\beta}}
$$

where $M_{0}^{(k)}$ denotes the $k$ th greatest moment in the population. Frohlich [2007] further defined an objective criterion to determine whether $R_{\Sigma}$ or $R_{k}$ constitutes a better estimate of $R$. Specifically, if for a given catalog (or subset of a cata$\log )$, the number of events $n$ greater than $M_{T}$ exceeds a number $N_{\text {large }}$ defined as

$$
N_{\text {large }}=\left(\frac{M_{C}}{M_{T}}\right)^{\beta},
$$

then $R_{\Sigma}$ is a reliable estimate of $R$. If, however, $n<N_{\text {large, }}$ then $R_{k}$ is preferable. In this study we specifically calculate $R_{5}$, which limits the sensitivity of the result to the greatest recorded moment. Finally, in equation (7), $M_{C}$ denotes a cutoff moment, i.e., a large moment above which the GutenbergRichter distribution tapers off. We estimate it systematically by fitting a tapered Gutenberg-Richter distribution [Kagan, 1997; Frohlich, 2007] to our catalog using a least squares approach (see Supporting Information).

With this method, combined with the 1000 random drawings of epicenter locations, we find a median moment release rate of our entire study area of $0.62 \times$ $10^{15} \mathrm{~J} / \mathrm{yr} / \mathrm{km}$, with 5th and 95th percentiles equal to $0.60 \times 10^{15}$ and $0.67 \times 10^{15}$ $\mathrm{J} / \mathrm{yr} / \mathrm{km}$, respectively (Figure $3 \mathrm{G}$ ). Further, the distributions of moment release rates at $D B$ and $A B$ sections appear wider, nonnormal, and show very little overlap (Figures $3 \mathrm{H}$ and $3 \mathrm{I}$ ). Moment release rates are significantly higher at DB sections (5th and 95th percentile: $0.71-0.90 \times 10^{15}$ $\mathrm{J} / \mathrm{yr} / \mathrm{km}$, median: $\left.0.79 \times 10^{15} \mathrm{~J} / \mathrm{yr} / \mathrm{km}\right)$ than at $A B$ sections (5th and 95th percentile: $0.13-0.53 \times 10^{15} \mathrm{~J} / \mathrm{yr} / \mathrm{km}$, median: $0.37 \times 10^{15} \mathrm{~J} / \mathrm{yr} / \mathrm{km}$ ), almost by a factor of 2 . These values are in agreement with independent estimates from the global CMT catalog, which yielded $0.23-0.82 \times$ $10^{15} \mathrm{~J} / \mathrm{yr} / \mathrm{km}$ for the entire portion of the MAR separating the North American and African plates [Frohlich and Wetzel, 2007].

The teleseismic catalog yields earthquake statistics that are robust, and representative of a time scale $T_{S}=43$ years, which is about an order of magnitude longer than the typical deployment of temporary seismic or hydro-acoustic arrays at the axis of the ridge. However, the relatively high detection threshold of 
A.

B.

Figure 5. (A) Cumulative seismic moment release as a function of time since 1 January 1999 measured at all concatenated AB sections (red curve) and DB sections (blue curves), using the ISC teleseismic catalog. The black line shows the moment release to be expected if the entire plate separation rate $(2.5 \mathrm{~cm} / \mathrm{yr})$ was accommodated purely seismically on a $45^{\circ}$-dipping fault reaching down to a $5 \mathrm{~km}$ depth. (B) Cumulative seismic moment release measured at each AB and DB section in the hydro-acoustic catalog.

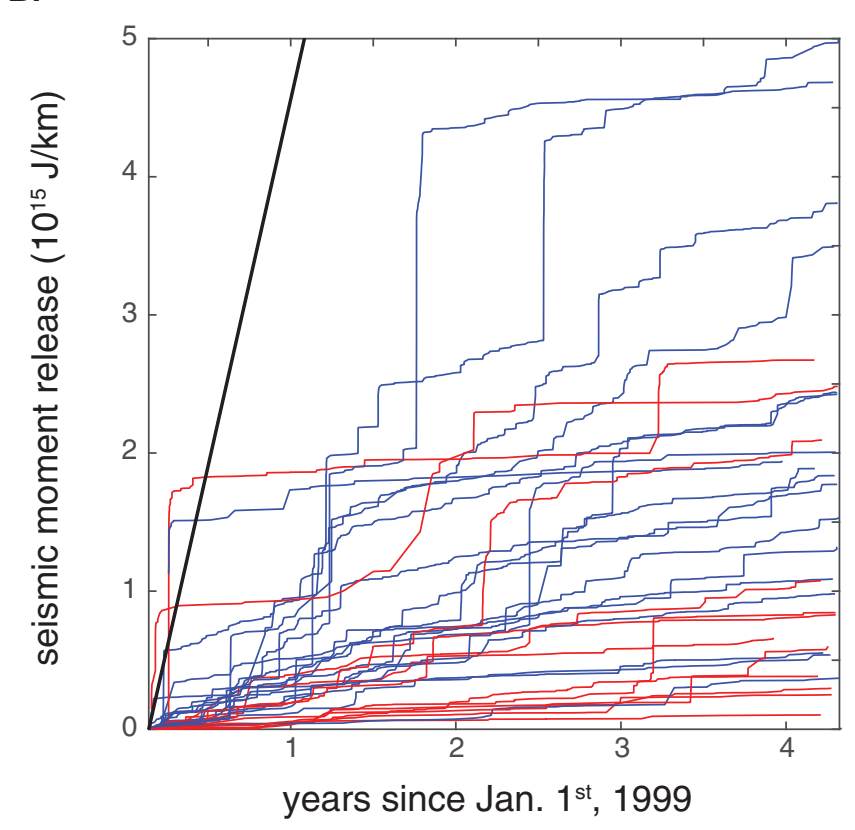

land-based teleseismic networks limits the total number of recorded earthquakes. This limitation, combined with large epicenter location uncertainties relative to the length of the shortest sections, precludes a reliable sectionby-section analysis of the catalog. To circumvent this difficulty, we turn to a 4 year long catalog recorded on a temporary hydro-acoustic array deployed near the ridge axis [Smith et al., 2003]. Since interpretations of hydro-acoustic source levels in terms of seismic moments are not straightforward, the remainder of this study largely focuses on relative changes in earthquake statistics across ridge sections, and rely on regional, longer-term averages from the teleseismic catalog to convert those acoustic values to absolute ones. In particular, we define a reference $\beta$-value $\left(\beta_{\text {ref }}=0.78\right)$ and a reference moment release rate for the Northern MAR. This rate $R_{\text {ref }}$ is simply the median $R$ estimated over our entire teleseismic catalog, and is equal to $0.62 \times 10^{15} \mathrm{~J} / \mathrm{yr} / \mathrm{km}$. The time frame spanned by the teleseismic catalog ( $T_{S}=43$ years) will also be used as reference a time scale to compare catalogs of shorter duration.

\section{Earthquake Statistics Across Sections From the 4 Year Long Hydro-acoustic Catalog}

\subsection{Data Set}

We assembled a comprehensive earthquake catalog from events recorded by the hydrophone array deployed near the axis of the ridge (Figure $2 \mathrm{~A}$ ) between January 1999 and September 2003 [Bohnenstiehl et al., 2000, 2002; Smith et al., 2002, 2003]. The data are available at http://www.pmel.noaa. gov/acoustics/autochart/GetPosit.html and as part of the Supporting Information. A total of 6433 events were selected and classified using the same criteria as the teleseismic catalog (section 3.1 and Figure $2 \mathrm{C}$ ). The characteristic $(2 \sigma)$ location uncertainty for this catalog is $\sim 2 \mathrm{~km}$ [Bohnenstiehl and Tolstoy, 2003], which is very small relative to the length of individual sections (30-130 km). On average, 214 earthquakes were recorded per section. This data set therefore enables a reliable section-by-section analysis of the seismicity of the Northern MAR.

Hydrophones record hydro-acoustic T-waves generated at the seafloor from the conversion of seismic waves, which then propagate through the water column within the SOFAR channel [e.g., Dziak et al., 2011]. Event size is therefore estimated from the amplitude of the T-wave signal corrected for propagation and 
A.

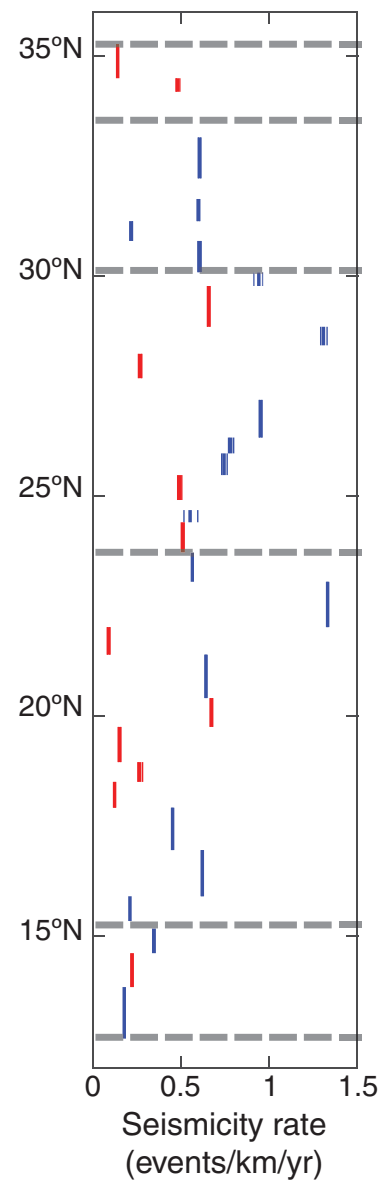

B.

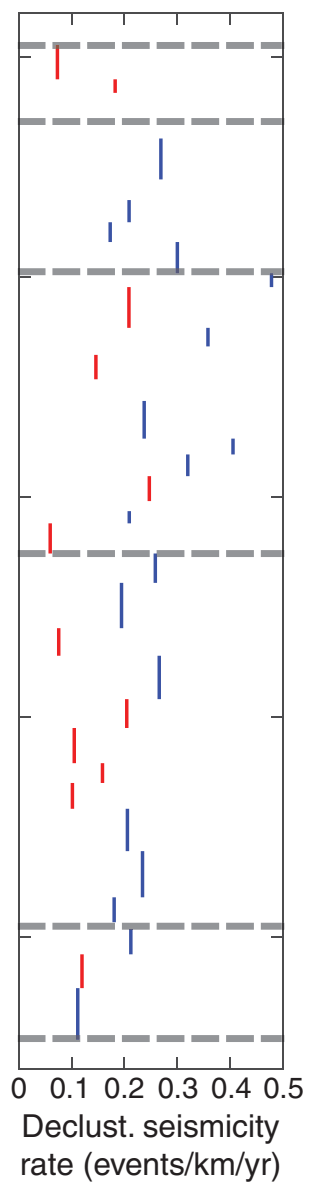

C.

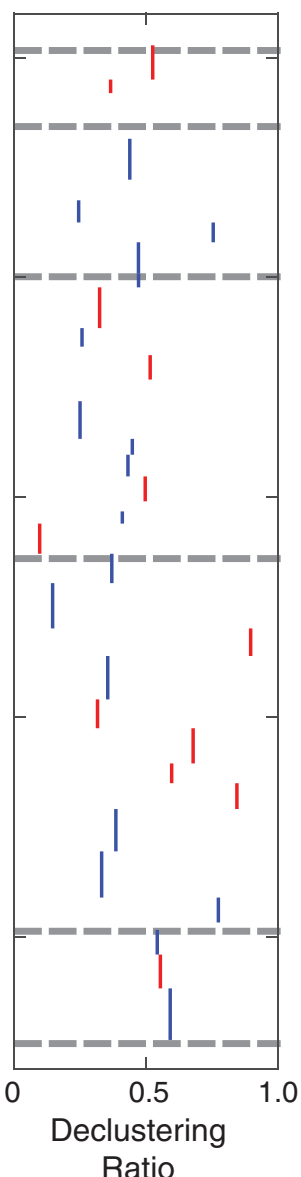

D.

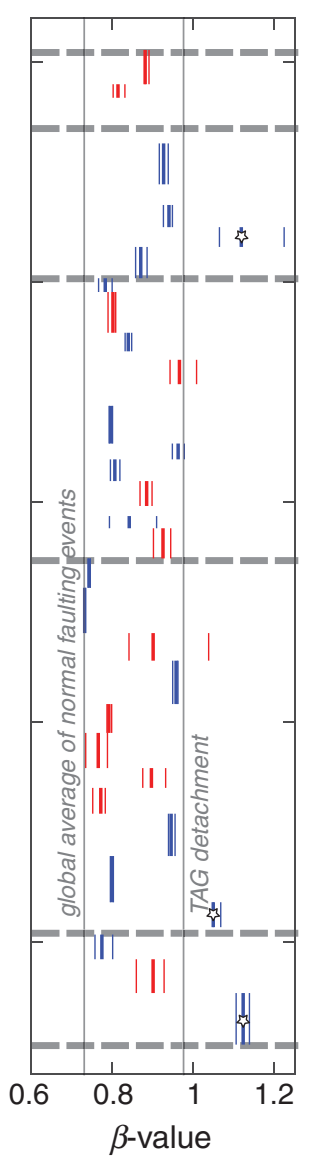

E.

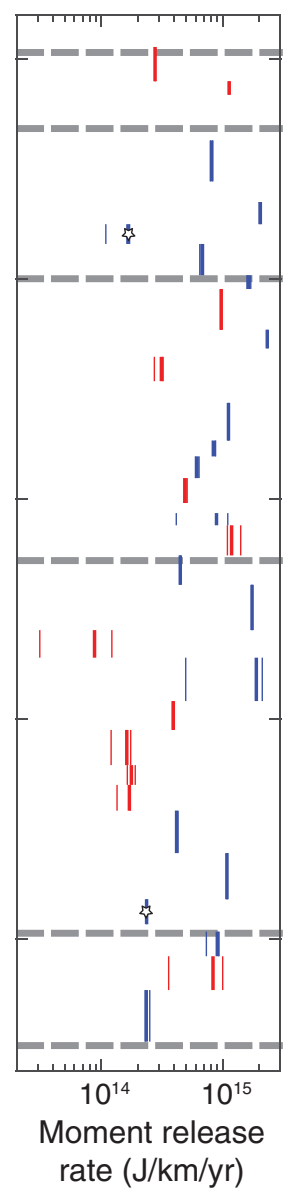

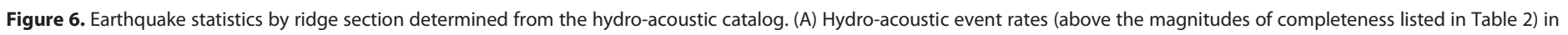

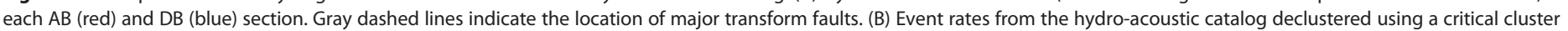

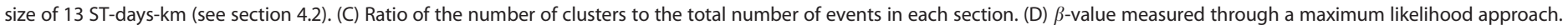

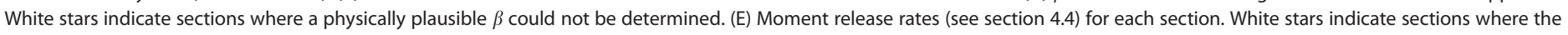
moment release rate may be less reliable due to a poor estimate of the $\beta$-value (see section 4.4). Figures $6 \mathrm{~A}, 6 \mathrm{D}$, and $6 \mathrm{E}$ show the result of 1000 analyses, with the median value as a bold segment and the 5th and 95th percentiles as thin segments.

instrument response [Smith et al., 2003]. This amplitude is expressed as a source level (S); that is, the acoustic energy in decibels $(\mathrm{dB})$ relative to $1 \mu \mathrm{Pa}$ pressure at $1 \mathrm{~m}$ above the seafloor. $\mathrm{n}$ the catalog, $S$ ranges between 191 and $239 \mathrm{~dB}$. In section 4.3, we will propose a method to estimate moment magnitude from source level. In the meantime, $S$ can be treated as a proxy for magnitude, and a source level of completeness of $202 \mathrm{~dB}$ can be estimated from the frequency versus $S$ distribution of the catalog, using the methodology described in section 3.2 (Figure 4A).

\subsection{Hydro-acoustic Seismicity Rates Across Ridge Sections}

We first focus on variations in seismicity rates across segments. Among the 6433 hydro-acoustically recorded earthquakes, 1679 (26\%) occurred on an $A B$ section, a proportion remarkably similar to that of the teleseismic catalog (24\%). Yet AB sections account for as much as $\sim 40 \%$ of the study area, which corroborates the idea of a lower characteristic seismicity rate in those sections. To better assess this hypothesis while taking location uncertainties into account, we follow the methodology described in section 3.1 and perform the below analysis 1000 times on independent random drawings of epicenter location using a 2- $\sigma$ uncertainty of $2 \mathrm{~km}$. In Figure 6A and Table 2, we report seismicity rates across all sections. We specifically show the 5th, 50th, and 95th percentiles of the segment-wise rate distributions that resulted from the 1000 drawings. Rates appear to be generally greater at DB sections. In fact, for every random drawing of epicenter locations, a two-sample Student's $t$ test overwhelmingly rejects the null hypothesis that seismicity rates 
Table 2. Seismogenic Properties of All Abyssal Hill (AB) and Detachment Bearing (DB) Sections Determined From the Hydro-acoustic Catalog (Section 4)

\begin{tabular}{|c|c|c|c|c|c|c|c|c|c|c|c|}
\hline $\begin{array}{l}\text { Section } \\
\text { Number }\end{array}$ & Type & $M_{w T}$ & $N_{>M w T}$ & $\begin{array}{l}\text { Event Rate } \\
(\mathrm{ev} / \mathrm{km} / \mathrm{yr})\end{array}$ & $\begin{array}{c}\text { Declust. Event } \\
\text { Rate (ev/km/yr) }\end{array}$ & $\begin{array}{l}\text { Declust. } \\
\text { Ratio }\end{array}$ & $\beta$ & $\begin{array}{c}R_{\text {inf }} \\
\left(10^{15} \mathrm{~J} / \mathrm{yr} / \mathrm{km}\right)\end{array}$ & $\begin{array}{c}R_{\text {med }} \\
\left(10^{15} \mathrm{~J} / \mathrm{yr} / \mathrm{km}\right)\end{array}$ & $\begin{array}{c}R_{\text {sup }} \\
\left(10^{15} \mathrm{~J} / \mathrm{yr} / \mathrm{km}\right)\end{array}$ & $H_{C}(\mathrm{~m})$ \\
\hline 1 & DB & 3.4633 & 92 & 0.1754 & 0.1118 & 0.5917 & 1.1229 & 0.2309 & 0.2347 & 0.2509 & 221 \\
\hline 2 & $A B$ & 3.3986 & 77 & 0.2197 & 0.1198 & 0.5545 & 0.9011 & 0.3592 & 0.8337 & 1.0025 & 786 \\
\hline 3 & DB & 3.3994 & 89 & 0.3436 & 0.2123 & 0.5426 & 0.7749 & 0.7351 & 0.9049 & 0.9345 & 853 \\
\hline 4 & DB & 3.326 & 54 & 0.2077 & 0.1808 & 0.7742 & 1.0492 & 0.2363 & 0.2363 & 0.2378 & 223 \\
\hline 5 & DB & 3.3372 & 300 & 0.6191 & 0.2345 & 0.3319 & 0.7999 & 1.0843 & 1.0857 & 1.0963 & 1024 \\
\hline 6 & DB & 3.2935 & 200 & 0.4502 & 0.2059 & 0.3858 & 0.9454 & 0.4095 & 0.4213 & 0.423 & 397 \\
\hline 7 & $A B$ & 3.2307 & 32 & 0.1205 & 0.1016 & 0.8444 & 0.7722 & 0.1348 & 0.1704 & 0.173 & 161 \\
\hline 8 & $A B$ & 3.1918 & 52 & 0.2627 & 0.1586 & 0.5972 & 0.8969 & 0.1639 & 0.177 & 0.1905 & 167 \\
\hline 9 & $A B$ & 3.0399 & 54 & 0.1494 & 0.1051 & 0.6786 & 0.766 & 0.1205 & 0.1623 & 0.1747 & 153 \\
\hline 10 & $A B$ & 3.0163 & 199 & 0.6709 & 0.2046 & 0.3162 & 0.792 & 0.3859 & 0.3924 & 0.3952 & 370 \\
\hline 11 & $\mathrm{DB}$ & 3.1961 & 291 & 0.6402 & 0.2662 & 0.355 & 0.9577 & 0.4967 & 1.8987 & 2.1247 & 1790 \\
\hline 12 & $A B$ & 3.021 & 24 & 0.0865 & 0.0757 & 0.8966 & 0.9011 & 0.0311 & 0.0879 & 0.1222 & 83 \\
\hline 13 & DB & 3.1542 & 636 & 1.3315 & 0.1947 & 0.1461 & 0.7325 & 1.747 & 1.7507 & 1.7532 & 1650 \\
\hline 14 & DB & 3.2045 & 174 & 0.562 & 0.2587 & 0.3704 & 0.7437 & 0.4453 & 0.4479 & 0.4508 & 422 \\
\hline 15 & $A B$ & 3.4723 & 155 & 0.5096 & 0.0596 & 0.0971 & 0.9254 & 1.0963 & 1.187 & 1.4109 & 1119 \\
\hline 16 & DB & 3.2303 & 60 & 0.5497 & 0.2094 & 0.4103 & 0.8423 & 0.4152 & 0.8911 & 1.1036 & 840 \\
\hline 17 & $A B$ & 3.2745 & 126 & 0.4908 & 0.2474 & 0.497 & 0.8852 & 0.4795 & 0.4909 & 0.5104 & 463 \\
\hline 18 & DB & 3.1847 & 166 & 0.7426 & 0.3203 & 0.4316 & 0.8068 & 0.5976 & 0.6155 & 0.6397 & 580 \\
\hline 19 & DB & 3.3503 & 125 & 0.7807 & 0.4059 & 0.4481 & 0.9627 & 0.8226 & 0.8534 & 0.8755 & 805 \\
\hline 20 & $\mathrm{DB}$ & 3.1929 & 374 & 0.9506 & 0.2377 & 0.25 & 0.7968 & 1.1104 & 1.1183 & 1.1231 & 1054 \\
\hline 21 & $A B$ & 3.3921 & 62 & 0.2665 & 0.1462 & 0.5158 & 0.9659 & 0.2737 & 0.3129 & 0.3233 & 295 \\
\hline 22 & $\mathrm{DB}$ & 3.3389 & 254 & 1.3076 & 0.3585 & 0.2575 & 0.84 & 2.3182 & 2.3363 & 2.357 & 2203 \\
\hline 23 & $A B$ & 3.3156 & 274 & 0.6555 & 0.2088 & 0.3242 & 0.8021 & 0.9631 & 0.9743 & 0.9839 & 919 \\
\hline 24 & DB & 3.3205 & 134 & 0.9403 & 0.4789 & 0.4717 & 0.7832 & 1.589 & 1.6403 & 1.7079 & 1546 \\
\hline 25 & DB & 3.2835 & 201 & 0.6031 & 0.3005 & 0.4714 & 0.8706 & 0.6486 & 0.6773 & 0.6966 & 639 \\
\hline 26 & DB & 3.2074 & 45 & 0.2161 & 0.1733 & 0.7547 & 1.1183 & 0.109 & 0.1658 & 0.1711 & 156 \\
\hline 27 & $\mathrm{DB}$ & 3.5542 & 137 & 0.5983 & 0.2091 & 0.2448 & 0.9401 & 2.0299 & 2.0377 & 2.0889 & 1921 \\
\hline 28 & DB & 3.3606 & 259 & 0.6035 & 0.2693 & 0.4385 & 0.927 & 0.7955 & 0.8102 & 0.8297 & 764 \\
\hline 29 & $A B$ & 3.4607 & 68 & 0.4774 & 0.1827 & 0.3659 & 0.8146 & 1.1253 & 1.1323 & 1.1489 & 1067 \\
\hline 30 & $A B$ & 3.4592 & 49 & 0.138 & 0.0733 & 0.5254 & 0.8814 & 0.2774 & 0.2774 & 0.2791 & 262 \\
\hline All & $A B$ & 3.23 & 1242 & 0.3477 & 0.1378 & 0.3657 & 0.7798 & 0.2327 & 0.2371 & 0.2506 & 431 \\
\hline All & $\mathrm{DB}$ & 3.23 & 3879 & 0.6771 & 0.2538 & 0.3509 & 0.7312 & 0.4537 & 0.4629 & 0.4659 & 841 \\
\hline All & & 3.23 & 5121 & 0.5498 & 0.2089 & 0.3547 & 0.7667 & 0.3750 & 0.3757 & 0.3764 & 683 \\
\hline
\end{tabular}

${ }^{a}$ Seismicity rates in the complete and declustered (section 4.2) catalogs as well as $\beta$-values are determined using events above a magnitude of completeness $M_{w T}$. 5th, $50^{\text {th }}$, and 95th percentiles from 1000 analyses are reported for the moment release rates as $R_{\text {int }}$ $R_{\text {med }}$ and $R_{\text {sup }}$ respectively. The corresponding coupled thickness $H_{C}$ is calculated using $R_{\text {med }}$ adjusted to a reference duration $T_{S}=43$ years, and equation (15).

measured on AB sections ( $n=12$ samples) and DB sections $(n=18)$ are drawn from distributions that have equal means with potentially different variance. The associated $P$-value averages 0.0082 . This strongly corroborates the conclusions of Escartín et al. [2008a].

One possibility not explored by Escartín et al. [2008a] is that changes in seismicity rates could reflect changes in the distribution of mainshock-aftershock sequences. For example, a greater net seismicity rate could be accounted for without any increase in the (background) rate of mainshock occurrence, but with a greater number of aftershocks triggered by each mainshock. To evaluate this possibility, we conducted a simple clustering analysis of the catalog. Specifically, all events falling within a critical space-time (ST) distance $D_{\text {crit }}$ from each other were reduced to a single event corresponding to the earliest, most energetic earthquake in the sequence (mainshock). For example, an ST distance of $30 \mathrm{ST} \mathrm{km} \mathrm{can} \mathrm{refer} \mathrm{to} \mathrm{simultaneous}$ events $30 \mathrm{~km}$ apart, collocated events occurring 30 days apart, or a combination of a space and time distance under $30 \mathrm{~km}$ and 30 days [Davis and Frohlich, 1991; Bohnenstiehl et al., 2002]. We choose a critical cluster size of $D_{\text {crit }}=13 \mathrm{ST} \mathrm{km}$, which constitutes a representative duration of mainshock-aftershock sequences [Bohnenstiehl and Tolstoy, 2003; Simão et al., 2010] from a data set that combines the hydro-acoustic catalog analyzed here as well as others extending further North of the Oceanographer Fracture Zone. For simplicity this procedure was only conducted once on the reported epicenter locations, as opposed to repeated 1000 times. The declustered catalog is shown in Figure 2D: each cluster of events is reduced to the largest (highest $S$ ) and earliest earthquake, whose source level is then compared to the level of completeness of the catalog to determine declustered seismicity rates (Figure 6B). Like nondeclustered rates, background rates appear generally greater at $D B$ sections relative to $A B$ sections. A $t$ test again overwhelmingly rejects the 
hypothesis that declustered event rates from each section type are drawn from distributions with equal means $\left(p=4.8309 \times 10^{-4}\right)$. It is thus plausible that differences in net seismicity rates primarily reflect differences in background seismicity rates. This would be consistent with the finding of Simão et al. [2010] that mainshocks on DB sections generate fewer aftershocks over shorter time scales than mainshocks on $A B$ sections.

In addition to declustered seismicity rates, we also computed declustering ratios (Figure 6C), i.e., the number of declustered events (both above and below the completion size) divided by the initial number of earthquakes in each section. A low ratio indicates a high degree of spatiotemporal clustering, perhaps indicative of a magmatic swarm as opposed to a mainshock-aftershock sequence that follows Omori's law [Schlindwein, 2012]. However, we found no statistically robust difference in declustering ratio between sections, and can therefore not conclude on the physical interpretation of the clustering.

\subsection{Inferring Seismic Moment From Hydro-acoustic Source Level}

As stated in section 4.1, hydro-acoustic source level is not a straightforward measure of the energy released during an earthquake. This is largely due to the complexity of the conversion of seismic waves into hydroacoustic waves on the seafloor, and their transmission through the water column. This process is strongly influenced by local topographic roughness, earthquake focal mechanism, path effects, and many other parameters, which introduce significant variability in the amplitude of the T-phase [Bohnenstiehl and Tolstoy, 2003; Pan and Dziewonski, 2005; Dziak et al., 2011]. However, the fact that the frequency versus $S$ distribution of the hydro-acoustic catalog resembles a Gutenberg-Richter law suggests that $S$ can be used as a proxy for moment magnitude, at least in a relative sense. In the following, we assume an affine mapping between seismic moment and source level:

$$
S=p_{1} \log _{10}\left(M_{0}\right)+p_{2}
$$

The first parameter $p_{1}$ can be determined upon evaluating the slope $\beta_{H}$ of the Gutenberg-Richter distribution of the hydro-acoustic catalog formulated in terms of source level

$$
\log _{10}\left(N_{\geq M_{0}}\right)=A_{H}-\beta_{H} S
$$

where $A_{H}$ is an intercept related to hydro-acoustic seismicity rates. Combining equations (3), (8), and (9) yields

$$
p_{1}=\frac{\beta}{\beta_{H}} .
$$

A maximum likelihood estimate yields $\beta_{H}=0.0601 \mathrm{~dB}^{-1}$ (with a completeness source level of $202 \mathrm{~dB}$ ). If we assume that the $\beta$-value determined from the entire teleseismic catalog $\left(\beta_{\text {ref }}=0.78\right)$ must apply to the hydro-acoustic catalog, we obtain $p_{1}=12.9902$ (Figure 4A).

To determine $p_{2}$, which acts as a multiplying factor over the entire distribution of hydro-acoustic moments, we postulate that the moment release rate of the entire study area calculated from the hydro-acoustic data should match the reference moment release rate $\left(R_{\text {ref }}=0.62 \times 10^{15} \mathrm{~J} / \mathrm{yr} / \mathrm{km}\right)$ determined from the teleseismic catalog. However, the order of magnitude difference in catalog time span requires an adjustment of the moment release rates. Frohlich [2007] specifically proposed that to compare Gutenberg-Richter distributed catalogs of different durations, one should adjust the moment release rate observed over a time span $T$ to a standard observation interval $T_{S}$, following:

$$
R_{\text {adjusted }}=R_{\text {observed }} \times\left(\frac{T_{S}}{T}\right)^{\frac{1}{\beta}-1} .
$$

In our case, adjusting rates measured over 4.18 years in the hydro-acoustic catalog to the $T_{S}=42.89$ year interval of the teleseismic catalog corresponds to multiplying the hydro-acoustic rates by 1.93 (assuming $\beta=\beta_{\text {ref }}=0.78$ ). After performing this correction, we determine the value of $p_{2}$ such that the median moment release rate from 1000 analyses of the hydro-acoustic catalog with random event locations matches $R_{\text {ref }}$. This yields $p_{2}=21.4565$. 
It should be noted that the value of $p_{2}$ affects subsequent estimates of seismic moment release rates (and ultimately seismic coupling) only in an absolute sense. None of the relative differences across different ridge sections reported here and in section 5 are affected by this value. However, to assess the plausibility of our mapping (Figure 4B), we rely on events that can be identified in both the teleseismic and hydro-acoustic catalogs. Such paired events are typically very close in time, but may appear spatially distant due to the large location uncertainty of the teleseismic catalog. We therefore only retain paired events distant by less than $15 \mathrm{~km}$, and compare their source level with their estimated moment magnitude (Figure 4B). Our mapping (equation (8)) is shown as a red line in Figure $4 B$, and falls on the high end of the cloud of paired events. It translates the source level of completeness of $202 \mathrm{~dB}$ into a moment magnitude of completeness of 3.23, which is in agreement with that estimated by Bohnenstiehl et al. [2002]. The mapping determined from paired events by Pan and Dziewonski [2005] is shown as a green dashed line in Figure 4B, and falls on the lower end of the cloud of paired events. This alternate mapping is not preferred here, as it predicts an unrealistically low magnitude of completeness for the hydro-acoustic catalog (e.g., $M_{w}<1$ for $\sim 202 \mathrm{~dB}$ ).

\section{4. $\beta$-Values and Moment Release Rates Across Sections}

Armed with estimates of moment magnitudes for the hydro-acoustic catalog, we can now evaluate systematic changes in $\beta$-values across ridge sections. Following the methodology outlined in section 3 , we first assess magnitudes of completeness for each section. These provide a more refined estimate than the global average of 3.23, and are used to estimate $\beta$ through a maximum likelihood approach (Figure 6D and Table 2 ), for each of the 1000 random drawings of epicenter locations. Physically impossible values of $\beta>1$ were systematically obtained at sections 1,4 , and 26 , perhaps due to a small number of events above the completeness threshold hindering the maximum likelihood method. Excluding these three anomalous locations, the mean completeness magnitude and $\beta$-value across sections are 3.29 and 0.85 , respectively. There does not appear to be any statistically significant difference between $\beta$-values measured at $A B$ versus $D B$ sections in any of the 1000 random drawings. A two-sample $t$-test can never reject the hypothesis that $\beta$-values measured at $A B$ and $D B$ sections are drawn from distributions of equal means (average $p=0.6188$ ). Interestingly, the $\beta$-values determined here are higher than the teleseismic average, which could be partly due to the short time window spanned by the hydro-acoustic data set. Finally, it is noteworthy that these $\beta$-values fall between the global mean value for normal faulting events ( 0.73) [Schorlemmer et al., 2005] and the $\beta$-value determined from a 1 year OBS deployment near the TAG detachment ( 0.98) [DeMartin, 2007] (Figure $6 \mathrm{D}$ and see section 5.2).

We next apply the methodology of section 3.3 to evaluate moment release rates at individual sections. Repeating the process 1000 times propagates the effect of location uncertainties. It also samples the sensitivity of moment release rate estimates to slight changes in $\beta$-value, if $R_{5}$ is deemed a better estimator than $R_{\Sigma}$ (see section 3.3 and equation (6)). This is the case at sections 4 and 26 , where the maximum likelihood method yielded an unrealistic $\beta$-value $>1$. At these two sections, we thus employ $R_{\Sigma}$ as an estimator even though the number of events above the completeness level is smaller than $N_{\text {large. }}$ However, we find that excluding these two sections from the subsequent analysis barely affects our results, and thus retain them. The results (5th, 50th, and 95th percentiles of 1000 analyses) are reported in Figure $6 \mathrm{E}$ and Table 2. In 81.2\% of random drawings, the $t$-test rejects the hypothesis that moment release rates measured at each section type are drawn from distributions of equal means (average $p=0.0289$ ). Figure $6 \mathrm{E}$ specifically shows overall greater moment release rates at $D B$ sections relative to $A B$ sections. This difference is also apparent in plots of the cumulative sum of seismic moments at individual sections (Figure 5B).

\section{Linking Ridge Seismogenesis and Long-Term Seafloor Spreading Processes}

In this section, we discuss our results in terms of the manifestation of contrasted modes of seafloor accretion on seismic cycle time scales. We first estimate seismically accommodated strain along the Northern MAR from our measurements of seismic moment release rates. We relate contrasts in seismically accommodated strain to the occurrence of active detachment faulting at the ridge axis. Then, we discuss the variations in geological and thermo-mechanical factors that may explain the observed variability in seismic moment release rates, and draw conclusions that inform our understanding of the seismogenic behavior of mid-ocean ridge normal faults. 


\subsection{Coupled Seismogenic Thickness Across Sections}

Seismic moment is a measure of energy that can be readily interpreted in terms of earthquake source parameters: $M_{0}$ scales as the product of the shear modulus times the rupture area times the characteristic earthquake slip. In this framework, the seismic moment release rate (normalized by unit length along the ridge axis, or fault strike) writes

$$
R=\frac{U_{S} G H}{\sin \theta}
$$

where $G$ is the shear modulus, $H$ is the vertical thickness over which seismic ruptures may occur, $\theta$ is the dip of the fault, and $U_{S}$ is the long-term seismic slip rate on the fault. On long time scales $\left(>10^{4}\right.$ year), the full rate of plate separation at the ridge, $U=2.5 \mathrm{~cm} / \mathrm{yr}$, is accommodated by a combination of crustal emplacement (e.g., melt bodies and dike intrusions into the lithosphere) and fault slip. Following Buck et al. [2005], we write $M$ the fraction of magmatically accommodated extension, and introduce $T=1-M$ : the fraction of tectonically accommodated extension. The average, long-term fault slip rate is therefore UT. We next define a coefficient of seismic coupling $\chi$, such that the fault slip accounted for by successive earthquakes writes $U T \chi$. Inserting these new parameters into equation (12) yields:

$$
R=\frac{U G(H T \chi)}{\sin \theta}
$$

Upon inspection of equation (13), we define one last parameter termed the coupled thickness $H_{C}$ [Frohlich and Wetzel, 2007]:

$$
H_{C}=H T \chi
$$

$H_{C}$ expresses the degree of seismic coupling on a given fault as a measure of thickness that can be straightforwardly interpreted in terms of geological and mechanical parameters. For example, a coupled thickness of $500 \mathrm{~m}$ could characterize a fault with a $500 \mathrm{~m}$ downdip width that grows exclusively by repeated earthquakes, or a $5 \mathrm{~km}$ wide fault whose growth is $90 \%$ aseismic, or in the context of a ridge: a $5 \mathrm{~km}$ wide fault growing purely seismically while $90 \%$ of the plate separation is taken up by magma emplacement. An infinite number of such combinations are possible, some of which will be further discussed in section 5.3 . In the meantime, we reformulate our estimates of seismic moment release rates (specifically, the median estimate of $R$ from 1000 analyses) as coupled thicknesses across all ridge sections, following:

$$
H_{C}=\frac{\sin \theta}{U G} R
$$

We assume a dip of $45^{\circ}$ for all ridge normal faults [Thatcher and Hill, 1995], including detachment faults, which are only low-angle in their exposed, flexurally rotated section, and that likely root to steeper angles at depth [Buck, 1988; Lavier et al., 1999; DeMartin et al., 2007; Morris et al., 2009; MacLeod et al., 2011; Choi and Buck, 2012]. We also assume $G=30 \mathrm{GPa}$, and report the results in Table 2. It should be noted that the framework described above applies regardless of whether tectonic extension is distributed on a single fault slipping at a rate $U \times T$, or on $n$ faults slipping at a rate $U \times T / n$. The reference moment release rate $R_{\text {ref }}$ identified at the end of section 3 corresponds to an average coupled thickness of $587 \mathrm{~m}$, in agreement with the estimates of Bird et al. [2002]. The coupled thickness measured at AB sections ranges between 83 and $1119 \mathrm{~m}$, and averages $487 \mathrm{~m}$ (Figure 6A). By contrast, the coupled thickness at DB sections is greater and averages $949 \mathrm{~m}$ while spanning a wider range between 156 and $2203 \mathrm{~m}$. The corresponding distributions are shown in Figure 7A.

\subsection{Seismic Coupling and the Occurrence of Detachment Faulting}

The distribution of coupled thicknesses at DB sections shows considerably greater spread than that of $A B$ sections (Figure 7A). This is consistent with the greater degree of along-axis morphological variability that characterizes DB sections (Figure 1). In particular, DB sections are defined by the occurrence of one or several detachment faults, which have a seafloor expression of finite along-axis extent. While the data sets analyzed in this study do not enable a precise determination of seismic coupling at the scale of an individual detachment ( $\sim 10-20 \mathrm{~km}$ ), they can be used to test ideas regarding the link between section-averaged seismic coupling and the occurrence of detachment faulting. 


\section{QAGU Geochemistry, Geophysics, Geosystems}

A.

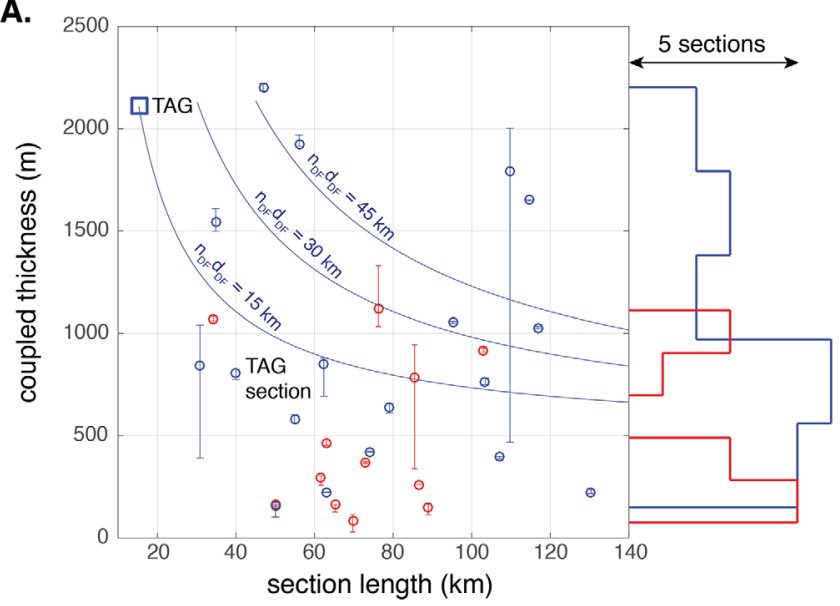

B.

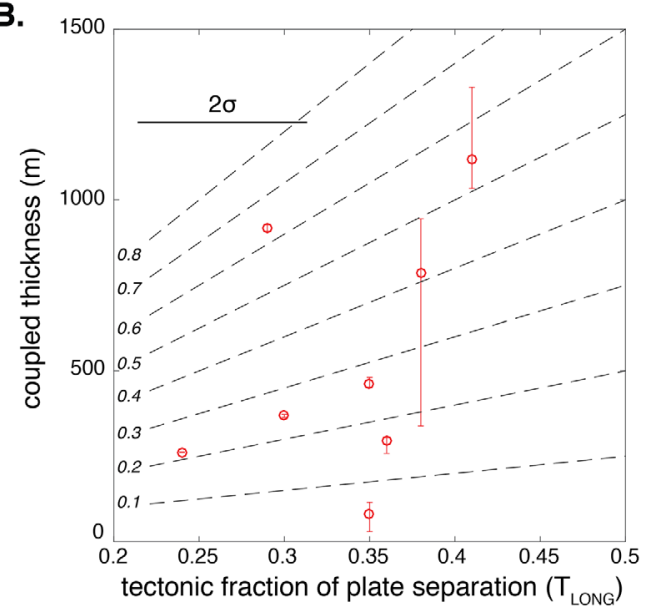

Figure 7. (A) Estimates of coupled thickness $H_{C}$ (equation (15)) as a function of section length for each $A B$ (red circles) and DB (blue circles) section. Vertical bars indicate the measure-

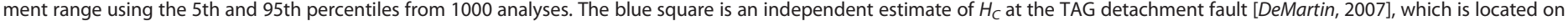
section 19 (TAG section). Blue dashed curves illustrate the expected dependence of $H_{C}$ on section length from the simple model described in section 5.2 , assuming each detachment fault has an along-axis extent of $d_{D F}=15 \mathrm{~km}$ (or that the along-axis extent of detachments is $15 n_{D F} \mathrm{~km}$ ). Distributions of coupled thicknesses at AB and DB sections are plotted on the

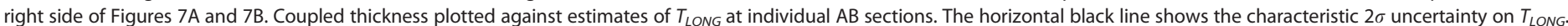
Black dashed lines show the expected correlation between $H_{C}$ and $T_{L O N G}$ under Scenario B of section 5.3, assuming $H=5 \mathrm{~km}$ and a given $\chi$ indicated next to each line (equation (14)).

Let us begin by comparing our results to independent estimates of moment release rate at the scale of a detachment fault, which requires the deployment of ocean bottom seismometers enabling enables precise event locations and magnitude estimates. Such a data set is to date only available for the TAG detachment fault at $26^{\circ} 08^{\prime} \mathrm{N}$ on the eastern side of the ridge axis, within our DB section 19 (Table 1). During this microseismic experiment (June 2003 to February 2004, i.e., a few months after the end of our hydro-acoustic catalog), 13 OBS were deployed in a $7 \times 7 \mathrm{~km}$ array and continuously recorded seismicity within the TAG massif [DeMartin et al., 2007]. Estimates of moment release rate yielded $R_{\Sigma}=2.1 \times 10^{15} \mathrm{~J} / \mathrm{yr} / \mathrm{km}$ by summing the moments of $\sim 10,000$ earthquakes [DeMartin, 2007]. Further, the Gutenberg-Richter distribution of this cata$\log$ has a $\beta$-value of $\sim 0.98$, and a cutoff moment about 3 orders of magnitude greater than the moment of completeness [DeMartin, 2007]. Equation (7) thus returns a value of $N_{\text {large }} \sim 1000$, much smaller than the number of recorded events. This suggests that $R_{\Sigma}$ represents a reliable estimate of moment release rate. For consistency, we adjust this value calculated over a catalog duration of $\sim 0.7$ year to our standard time scale $T_{S}$ using equation (11). We obtain an adjusted rate of $2.3 \times 10^{15} \mathrm{~J} / \mathrm{yr} / \mathrm{km}$, which translates into a coupled thickness of $2140 \mathrm{~m}$.

This estimate of coupled thickness for the TAG detachment is greater than all coupled thicknesses measured elsewhere on the ridge except at DB section 22 (Table 2). It is also considerably greater than our estimate of coupled thickness for DB section 19 (804 m), which contains the TAG detachment (Figure 7A). A possible explanation is that within a DB section, the coupled thickness may only be significantly greater than the regional average within individual detachment faults of finite along-axis extent. Normalizing the measured moment release rates by the length of the entire section would then "dilute" the signature of individual detachment faults. This model makes testable predictions of $H_{C}$ versus section length, $L$. For example, Figure 8A illustrates a scenario where all DB sections are made up of $n_{D F}$ active detachment faults of along-axis extend $d_{D F}$ and coupled thickness $H_{C}^{D F}$, separated by faulted areas morphologically similar to $A B$ sections, which may therefore have a similar coupled thickness, $H_{C}^{A H}$. Normalizing moment release rates by section length leads to the following relation between the apparent coupled thickness of the entire DB section $\left(H_{C}^{D B}\right)$ and its length

$$
H_{C}^{D B}=H_{C}^{A H}+\left(H_{C}^{D F}-H_{C}^{A H}\right) \frac{n_{D F} d_{D F}}{L}
$$

This relation is plotted in Figure 7A, using the coupled thickness of the TAG detachment for $H_{C}^{D F}$, and the average coupled thickness measured at $A B$ sections $(487 \mathrm{~m})$ for $H_{C}^{A H}$. We also assume $d_{D F}=15 \mathrm{~km}$, and plot three cases corresponding to $n_{D F}=1,2$, and 3 in Figure $7 \mathrm{~A}$ (blue curves). 
A.

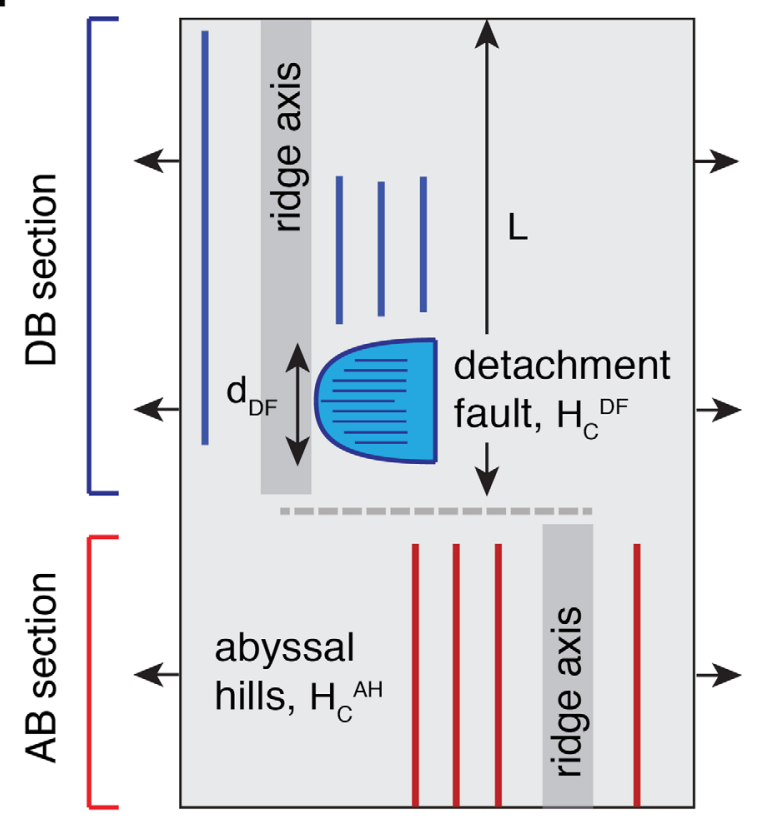

D.

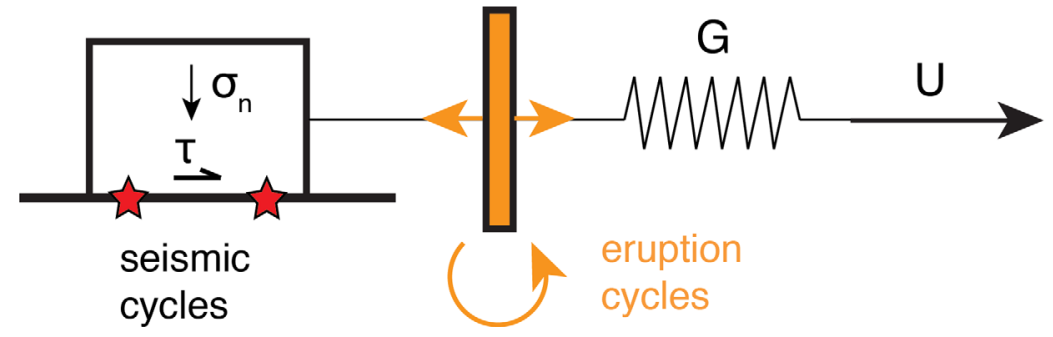

B.
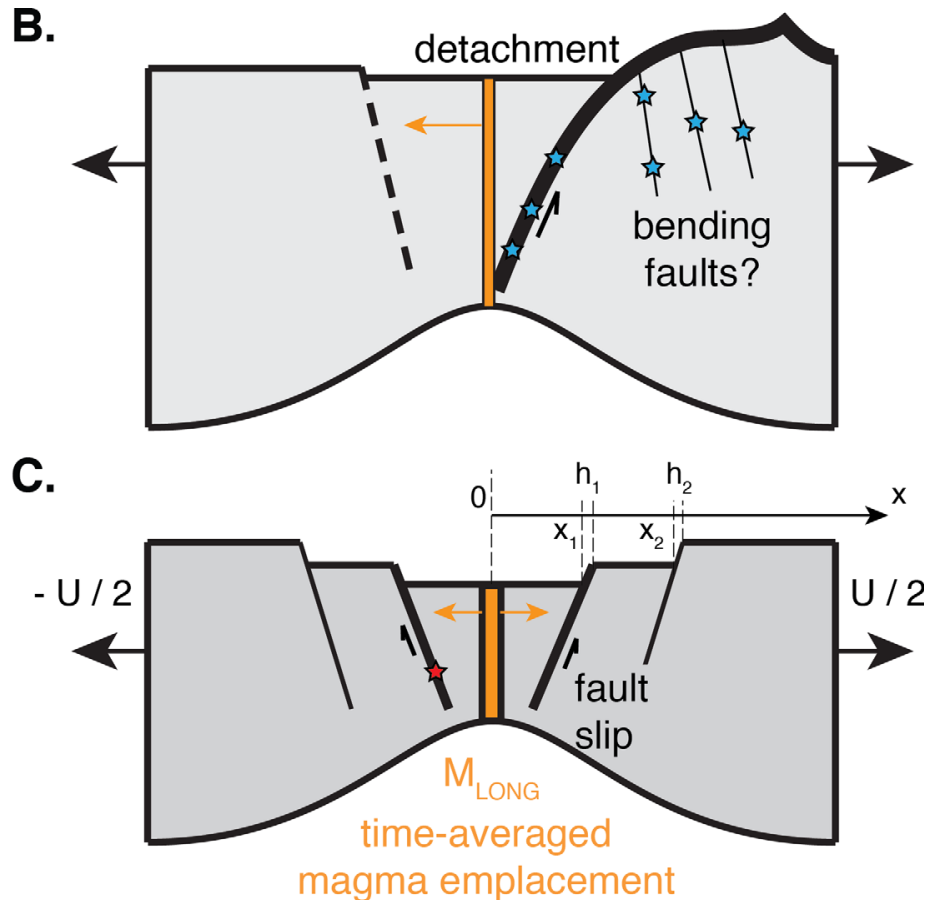

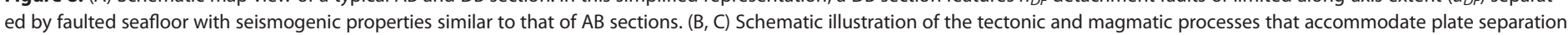

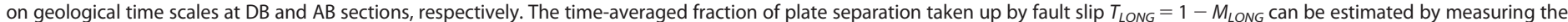

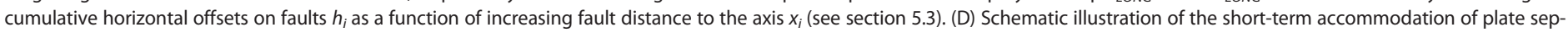

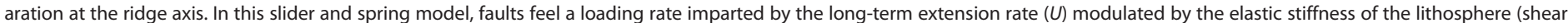
modulus $G$ ) and the periodic emplacement of dikes at the axis. Whether faults respond by aseismic creep or earthquakes (stars) depends on frictional properties that relate shear stress $(\tau)$ to effective normal stress $\left(\sigma_{n}\right)$.

This simple model can explain the difference between the coupled thickness measured at the TAG detachment fault, and the much lower effective coupled thickness averaged over the entire TAG section. In addition, it can explain the large coupled thickness of DB section 22 (the largest in our data set) by having the section host three active TAG-like detachment faults of limited along-axis extent $(\sim 15 \mathrm{~km})$. Although a detailed geological and geophysical characterization of section $22\left(28^{\circ} 25^{\prime}-28^{\circ} 51^{\prime} \mathrm{N}\right)$ is not yet available, the bathymetry reveals morphological similarities with the TAG section and suggests that it could plausibly feature several TAG-like structures [Escartín et al., 2008a].

While this model accounts for a large part of the spread of coupled thicknesses among DB sections, it fails to account for DB sections longer than $\sim 100 \mathrm{~km}$ that have high $H_{C}>1500 \mathrm{~m}$. Additional complexity must therefore be taken into account. For example, it is possible that detachment faults may extend further along-axis than their seafloor expression as the corrugated surface of a local topographic high [Reston and Ranero, 2011]. In our model, $n_{D F} d_{D F}$ represents the true extent of detachment faults, whose length can be as large as $\sim 45 \mathrm{~km}$ along-axis, although partially buried by hanging wall material.

In this simple framework, the existence of sections identified as DB, and yet characterized by a coupled thickness smaller than the $A B$ section average (e.g., section 14, south of the Kane Fracture Zone, with 
$H_{C}=422 \mathrm{~m}$ ) would suggest that the detachments hosted on these sections may no longer be active and be in fact rafted off-axis, which is the case of the Kane detachment. Alternatively, these detachments may be anomalous from a lithological or thermo-mechanical point of view (see section 5.4). Refined estimates of moment release rates along-axis paired with a more detailed seafloor characterization will be needed to further test the ideas put forward in this study. If our hypothesis is confirmed, elevated moment release rates measured in $\sim 10 \mathrm{~km}$ along-axis bins could constitute a signature of active detachment faulting. We cannot, however, discard the possibility that these elevated rates integrate both seismic slip on the detachment fault itself and seismic ruptures on secondary faults that do not directly accommodate plate separation, but are related to the growth of detachments (Figure 8B). For example, the microseismicity study of DeMartin et al. [2007] revealed strong seismic activity east of the main TAG fault, possibly related to antithetic bending faults that accompany the flexural readjustment of the TAG footwall [e.g., Buck, 1988]. Detailed studies of moment release rates at the scale of individual structures are needed to move this discussion forward. For the remainder of this study, we will discuss the high moment release rates of detachments as indicative of a high state of seismic coupling on this unique type of fault.

\subsection{Interpreting Measurements of Coupled Thickness}

We now propose and assess potential explanations for the differences in coupled thickness between $A B$ and $\mathrm{DB}$ sections. We continue to follow the reasoning introduced in section 5.2 and assume that the observed distribution of seismic moment release rates on the ridge reflects two end-member states of seismic coupling on two end-member types of normal faults. On the one end, detachment fault systems are characterized by a large coupled thickness $\left(H_{C}^{D F} \sim 2000 \mathrm{~m}\right.$ ). On the other hand, a background state of moderate coupling $\left(H_{C}^{A H} \sim 500 \mathrm{~m}\right.$ ) characterizes abyssal hill-type faults as well as portions of DB sections not taken up by detachment faults. This amounts to a factor of 4 difference in coupled thickness between the two end-members, which can be expressed as

$$
\frac{H_{C}^{D F}}{H_{C}^{A H}}=\frac{H_{D F} T_{D F} \chi_{D F}}{H_{A H} T_{A H} \chi_{A H}} \sim 4 .
$$

In this simple framework, we can use independent constraints on the seismogenic layer thickness $(H)$ and the fraction of tectonic extension $(T$ ) to narrow down the range of parameters making up the coupled thicknesses in equation (17).

The thickness of the seismogenic layer, which determines the extent of the fault prone to seismic rupture, can be estimated from the spatial distribution of microseismicity recorded on temporary fault-scale OBS arrays. Data sets available for the center of abyssal hill-type segments show micro-earthquakes occurring down to a depth of 5-6 km (e.g., at $29^{\circ} \mathrm{N}$ [Wolfe et al., 1995], at $35^{\circ} \mathrm{N}$ [Barclay et al., 2001], and at $7^{\circ} \mathrm{S}-8^{\circ} \mathrm{S}$ [Grevemeyer et al., 2013]). By contrast, microseismicity on detachment systems such as TAG $\left(26^{\circ} 08^{\prime} \mathrm{N}\right)$ and Logatchev $\left(14^{\circ} 45^{\prime} \mathrm{N}\right)$ can extend down to $7-8 \mathrm{~km}$ [DeMartin et al., 2007; Grevemeyer et al., 2013], but is very scarce within the first $2 \mathrm{~km}$ beneath the seafloor. Thus, the fault area prone to seismic rupture may not be very different between detachment and abyssal hill faults $\left(H_{D F} / H_{A H} \sim 1\right)$.

Constraining the tectonic fraction of plate separation, however, is not as straightforward. In the conceptual framework developed by Buck et al. [2005], continuous emplacement of igneous crust in the axial lithosphere accommodates a fraction $(M)$ of the total plate separation, while the remaining fraction $(T)$ is taken up by continuous slip on normal faults. This approach represents a time-averaged view of multiple diking and fault slip events (Figures $8 \mathrm{~B}$ and $8 \mathrm{C}$ ), and is thus valid on time scales relevant to abyssal hill or detachment fault growth (>10 kyr) [Olive et al., 2015]. On seismic cycle time scales, however, the discrete nature of magmatic events cannot be ignored (Figure 8D). For example, if the magmatic fraction of plate separation were entirely accommodated by repeated intrusions of meter-wide dikes at the ridge axis [Qin and Buck, 2008], the recurrence time of such events on the slow spreading MAR would be between 50 and 80 years, assuming $M$ ranges between 0.5 and 0.8 . If we further assume that each dike spans $\sim 20 \mathrm{~km}$ along-axis [e.g., Fialko and Rubin, 1998], we should expect $\sim 2$ intrusion events every year along our $2600 \mathrm{~km}$ long study area. Such events can sometimes be identified in hydro-acoustic or OBS catalogs if they are accompanied by a seismic sequence that features a clear spatial propagation of the earthquakes, and a lack of Omoristyle temporal decay in event rates, which would otherwise characterize a purely tectonic mainshockaftershock sequence [Dziak et al., 2004; Simão et al., 2010]. 
Simão et al. [2010] identified two sequences with this signature in the 4 year long catalog analyzed in section 4. This minimum number is consistent with our long-term expectation and supports the idea that the recurrence time of intrusion events is longer than the span of our teleseismic catalog. This then prompts the question of whether the loading rate of normal faults that leads to seismic slip on decadal time scales reflects $(A)$ the full plate separation rate, or (B) only the nonmagmatically accommodated extension rate. In other words, it is unclear whether the effective value of $M$ felt by faults in between discrete magmatic intrusion events $\left(M_{S H O R T}\right)$ is equal to 0 (Scenario $A$ ), to the long-term average $M_{L O N G}$ that controls the morphology of the seafloor (Scenario B) [Buck et al., 2005; Behn and Ito, 2008; Ito and Behn, 2008; Tucholke et al., 2008; Olive et al., 2015], or to some intermediate value $M_{I N T}$ (Scenario C).

A scenario like $B$ or $C$ is feasible if the stress perturbation induced by the intrusion of a dike in young axial lithosphere can be (1) felt by actively growing normal faults, and (2) sustained over the recurrence interval of magmatic intrusions. Scenario $\mathrm{A}\left(M_{S H O R T}=0\right)$ would be favored if dike intrusion stresses are rapidly relaxed and/or barely affect the stress state of active faults that are too far $(5-20 \mathrm{~km})$ from the neovolcanic zone where diking occurs. Discriminating between these scenarios is challenging without a continuous monitoring of axial deformation (e.g., seafloor geodesy, absolute pressure gauges, etc.) over sufficiently long periods of time. Interestingly, geodetic measurements in the Afar region suggest rapid ( $\sim 1$ year) visco-elastic stress relaxation following a dike intrusion event [e.g., Nooner et al., 2009], which would favor Scenario A.

Scenario $B\left(M_{S H O R T}=M_{L O N G}\right)$ makes the testable prediction that coupled thickness in a given section type should correlate with the long-term fraction of tectonically accommodated extension $T_{\text {LONG. This fraction }}$ may be estimated through the cumulative sum of fault heaves on each side of the ridge axis [Escartín et al., 1999]. We followed this methodology to estimate $T_{\text {LONG }}$ at a few ridge sections where bathymetry data spanning 0 to $\sim 1$ Myr old crust was available on GeoMap App [Ryan et al., 2009]. We considered only $A B$ sections, as their regular and symmetric morphology facilitates a reliable estimate of $T_{\text {LONG }}$ (Figure 7B) compared to DB sections [e.g., Schouten et al., 2010], where estimates of horizontal strain are less straightforward. Our estimates range between $0.24 \pm 0.1$ and $0.41 \pm 0.1$, in agreement with the previous estimate of $0.29 \pm 0.08$ measured by Ito and Behn [2008] at section 23 (Table 1). Upon plotting coupled thickness versus $T_{\text {LONG }}$ at these $A B$ sections (Figure $7 \mathrm{~B}$ ), we find no clear correlation between these two observables. This may not be too surprising given the large discrepancy in time scale sampled by these two quantities (4-40 years versus $\sim 1 \mathrm{Myr}$ ): indeed, $T_{\text {LONG }}$ would fail to record changes in strain partitioning on time scales greater than $\sim 100$ years but shorter than 1 Myr that could influence the present-day $H_{C}$.

In the absence of strong geological evidence for or against Scenario $B$ and $C$, we assess the implications of each end-member assumption ( $A$ and $B$ ) for estimating the seismic coupling coefficient. In Scenario $A$, $M_{S H O R T}=0\left(T_{S H O R T}=1\right)$ at both detachment and abyssal hill faults (Figure $\left.8 \mathrm{~B}\right)$, therefore $T_{D F} / T_{A H}=1$, and equation (17) yields $\chi_{D F} / \chi_{A H} \sim 4$. In Scenario $B$, however, estimating $\chi$ requires a constraint on $T_{S H O R T}=T$ LONG. Following our estimates of $T_{\text {LONG }}$ at $\mathrm{AB}$ sections (Table 1 and Figure $7 \mathrm{~B}$ ), 0.3 is a reasonable average for $T_{A H} . T$ is notoriously harder to constrain at detachment faults, but values around $0.5-0.6$ have been proposed on the basis of modeling studies [Buck et al., 2005; Tucholke et al., 2008; Olive et al., 2010] and in situ measurements [Schouten et al., 2010; Paulatto et al., 2015]. The corresponding ratio of $T_{D F} / T_{A H} \sim 2$ would therefore result in $\chi_{D F} / \chi_{A H} \sim 2$. Thus, the inference of a greater coupling coefficient on detachment faults (by a factor of 2-4) appears robust regardless of the assumption made on $T_{S H O R T}$, because the short-term rate of tectonic extension only modulates the absolute value of the coupling coefficient. Under Scenario $A$, the parameters of equation (17) quantified above suggest $\chi_{A H} \sim 0.1$ and $\chi_{D F} \sim 0.4$, while under Scenario $B$ greater values of $\chi_{A H} \sim 0.3$ and $\chi_{D F} \sim 0.6$ would be favored.

\subsection{Seismically Determined Coupling Coefficients and the Mechanical Properties of Oceanic Normal Faults}

Our estimates of seismic moment release rates along the Northern MAR suggest that the amount of slip accommodated by earthquakes on both abyssal hill and detachment faults is significantly lower than their inferred long-term slip rates. These estimates are carried out in a way that minimizes sensitivity to the biggest, rarest events in the catalog [Frohlich, 2007]. In addition, seismic events below the detection threshold of hydrophones are unlikely to make up for the missing strain if the observed Gutenberg-Richter distribution of earthquakes holds at magnitudes lower than $\sim 3$. The observed seismic deficit therefore suggests 
that most of the slip on oceanic normal faults occurs through some form of aseismic creep. Seafloor pressure measurements at the Hikurangi subduction zone in New Zealand have recently shown slow slip events equivalent to a magnitude 6.8 earthquake taking place over several weeks on a subduction interface, within depths of $\sim 2-7 \mathrm{~km}$ [Wallace et al., 2016]. This mode of transient slow creep is thus possible in shallow crust even in close proximity to the seafloor, and thus at low pressures and temperatures. Slow slip events could therefore be the primary mode of normal fault slip at mid-ocean ridges, and seismic ruptures may not play a key role in accumulating offset.

The mechanical factors that might generally inhibit seismic slip and favor slow slip on oceanic normal faults are poorly understood. Let us begin by briefly reviewing the (inferred) thermo-mechanical and lithological characteristics of these systems. At slow spreading ridges, seismogenic faults reach maximum depths of $\sim 6-8 \mathrm{~km}$, which likely correspond to the thermally controlled brittle-ductile transition. We therefore expect average fault temperatures below $\sim 600^{\circ} \mathrm{C}$ [e.g., Mackwell et al., 1998; Hirth et al., 1998] throughout this lithospheric thickness. Assuming hydrostatic fluid pressures, the effective normal stress on the fault plane should span $\sim 20-150 \mathrm{MPa}$. In magmatically robust $A B$ sections where the oceanic crust is $6-8 \mathrm{~km}$ thick, the primary fault lithologies should consist of basaltic and gabbroic gouges, and their alteration products (e.g., chlorite and amphibolite). By contrast, detachment faults are known to host a variety of mafic to ultramafic lithologies (gabbro and peridotites in addition to basalt), with complex alteration assemblages that include serpentinite, talc, chlorite, and tremolite [e.g., Escartín et al., 2003; Karson et al., 2006; Ildefonse et al., 2007; Dick et al., 2008; Picazo et al., 2012]. The large and highly localized strains associated with detachment faulting may also favor the formation of highly deformed mylonite and ultra-mylonite gouges at high temperatures [e.g., Hansen et al., 2013]. Highly deformed and altered lithologies such as talc or serpentinite are generally thought to render oceanic detachments weaker than abyssal hill faults, thus promoting long-lived strain localization at DB sections [e.g., Escartín et al., 1997; Schroeder and John, 2004]. It may therefore appear paradoxical that oceanic detachments be associated with greater amounts of seismogenic slip compared to abyssal hill faults if they are indeed weaker, but many other factors may also play a role such as pore fluid pressure or compositional heterogeneity and its geometry.

The relationship between the inferred long-term strength of a fault and its seismogenic behavior is not straightforward. While the former is largely controlled by the coefficient of static friction, the latter depends on how friction evolves at high (seismic) slip rates, which is empirically described by the theory of rate and state friction [Dieterich, 1979; Ruina, 1983; Scholz, 1998]. Velocity-weakening materials experience a drop in dynamic friction in response to an increase in slip velocity. This drop can lead to a frictional instability if the characteristic size over which it occurs is greater than a critical earthquake nucleation size $h^{*}$ [Rice and Ruina, 1983], given by

$$
h *=\frac{2}{\pi} \frac{b G d_{C}}{(1-v)(b-a)^{2} \sigma_{n}},
$$

where $G$ is the shear modulus of the gouge material, $v$ is Poisson's ratio, and $\sigma_{n}$ is the effective normal stress acting on the fault (Figure 8D). A velocity-weakening material is characterized by $(a-b)<0$, where $a$ and $b$ are parameters of the rate and state friction law [e.g., Marone, 1998]. $d_{C}$ is the characteristic distance over which the frictional state variable evolves after a change in slip rate, and can be thought of as the distance over which surface contacts between microscopic asperities are fully renewed during fault slip. Equation (18) is specifically valid for dip-slip (mode II) rupture in 2-D, where the along-strike extent of the fault greatly exceeds its width [Rubin and Ampuero, 2005]. It illustrates the fact that the gouge stiffness $(G)$ and stress state strongly determine whether slip perturbations in a velocity-weakening material can go unstable.

Experimental data on the frictional properties of oceanic fault materials over a wide range of temperature and pressure conditions remain scarce, and show significant sensitivity to the modal mineralogy of the sample and to the experimental conditions. For example, basaltic materials under moderate stress $(\leq 40 \mathrm{MPa})$ exhibit velocity-weakening behavior when subjected to slip rates up to a few meters per second, and the weakening mechanism is largely controlled by frictional heating and melting [Violay et al., 2014]. Experiments on wet gabbro gouges [He et al., 2007; Mitchell et al., 2015] indicate velocity-strengthening behavior at low temperatures $\left(<200^{\circ} \mathrm{C}\right)$ across a wide range of pressures. A narrow range of temperatures $(\sim 200-$ $300^{\circ} \mathrm{C}$ ) enables velocity-weakening behavior at high effective pressures ( $\left.\sim 200 \mathrm{MPa}\right)$. This range widens $\left(\sim 200^{\circ} \mathrm{C}\right.$ to at least $\left.600^{\circ} \mathrm{C}\right)$ at lower effective pressures $(\leq 30 \mathrm{MPa})$. Assuming a standard magmatic crust 
structure at AB sections [e.g., Sinton and Detrick, 1992], gabbroic gouge likely makes up the lower $\sim 50-70 \%$ of an abyssal hill fault and is plausibly subjected to temperatures in the $\sim 200-600^{\circ} \mathrm{C}$ range. Therefore, to first-order, an abyssal hill fault made up of shallow basalt and deep, hot gabbro could be primarily velocity weakening, with uncertainties arising from the lack of data in the range of 40-200 MPa. By contrast, the frictional behavior of gabbro bodies exhumed in a detachment fault will strongly depend on their temperature, and thus indirectly on the depth at which they sit. Shallow gabbroic units that have cooled below $\sim 200^{\circ} \mathrm{C}$ could be velocity strengthening, while deeper, hotter gabbros should be velocity weakening and earthquake-prone.

In the case of detachments, these magmatic units may be embedded in large tracts of serpentinized mantle and other alteration products. The resulting heterogeneous lithosphere thus has a complex frictional behavior, with variations at spatial length scales that are unconstrained. Alteration products (serpentinite, talc) tend to be weak, but they exhibit a complex behavior. While serpentine may transition from velocity strengthening to velocity weakening at faster slip rates [Reinen et al., 1991], this transition is inhibited at higher temperatures. Velocity-strengthening behavior favoring stable slip has been observed up to $700^{\circ} \mathrm{C}$ [Moore et al., 1997; Chernak and Hirth, 2010]. Talc, which is common along detachments, shows in contrast velocity strengthening behavior at temperatures $\angle 400^{\circ} \mathrm{C}$ [Moore and Lockner, 2011], but evidence for velocity-weakening behavior at high temperature [Escartin et al., 2008b], and talc-serpentinite mixtures show a complex behavior with both velocity strengthening and weakening properties [Moore and Lockner, 2011]. The frictional behavior of lithologically heterogeneous detachment faults is therefore highly sensitive to the mineralogy of the lower crust and mantle units (and the associated alteration products) that they exhume. Finally, pervasive circulation of fluids in and around detachment faults [e.g., McCaig et al., 2007] may further modify the effective confining pressure along the fault, thereby adding another source of strength heterogeneity to an already complex lithological structure.

In light of the great degree of heterogeneity observed in fault rocks, and the limited constraints from friction experiments, a straightforward way of interpreting our observation of a greater seismic coupling coefficient at detachments is to infer that a larger portion of the fault plane is capable of nucleating (or at least propagating) ruptures at seismic slip rates. The inferred value of $\chi \sim 0.4-0.6$ at detachment faults could indicate that seismic slip only occurs within one or several fully coupled patches that make up $\sim 50 \%$ of the fault area, while the rest of the fault can only creep aseismically. Velocity-weakening gabbro bodies at temperatures greater than $200^{\circ} \mathrm{C}$, or areas of weak alteration products are plausible candidates for such patches. Seismic ruptures nucleating in these weak patches could partially propagate through adjacent altered material that may be dominantly velocity strengthening, but mildly velocity weakening at high slip rates. Such control of lithological heterogeneities on seismic coupling has been invoked by McGuire et al. [2012] to explain why large earthquakes on some oceanic transform faults (e.g., the Gofar transform) repeatedly break only a fraction of the total fault surface. This conceptual framework, however, does not straightforwardly explain the lower seismic coupling coefficient of abyssal hill faults, which are thought to be more homogeneous and exhibit mainly velocity-weakening behavior.

Equation (18) indicates that velocity-weakening properties are necessary, but not sufficient to nucleate frictional instabilities. Another key condition is that slip perturbations must occur on a length scale greater than $h^{*}$ in order to become unstable. This requires that the velocity-weakening portion of oceanic normal faults cover a sufficiently wide area $\left(\geq h^{*}\right)$. Therefore, even in the end-member scenario where the entire extent of both abyssal hill and detachment faults is velocity-weakening (e.g., with widespread talcserpentine mixtures in detachment faults), shallower abyssal hill faults may not have enough area to easily nucleate seismic ruptures compared to detachments. Numerical simulations testing this conceptual model [Liu et al., 2012] show that slip on transforms can be multimodal, alternating between episodes of seismic and aseismic slip rupturing the velocity-weakening area of the fault. This behavior is favored when the width of the velocity-weakening area of the fault $(W=H / \sin (\theta)$ for normal faults with velocity-weakening material down to depth $H$ ) is comparable to the characteristic earthquake nucleation size. Specifically, $\mathrm{W} \ll$ $h^{*}$ promotes purely aseismic slip on the entire fault $(\chi=0)$, while $W \gg h^{*}$ leads to fully coupled, purely seismic slip $(\chi=1)$. Intermediate values of $W / h^{*}$ between 1 and 2 lead to a sharp increase in $\chi$ between 0 and 1 , and promote a mixed mode of fault slip where episodes of slow creep alternate with ruptures at seismic speeds. At slow mid-ocean ridges, the contrast in $\chi$ between detachment and abyssal hill faults may thus result from $W / h^{*}$ lying in the highly sensitive 1-2 range. The width of a detachment fault averaging a 
$45^{\circ}$-dip could be $W_{D F}=H_{D F} / \sin (\theta) \sim 10 \mathrm{~km}$, potentially more if one factors in fault curvature [DeMartin et al., 2007]. By contrast, the width of an abyssal hill fault could be as short as $7 \mathrm{~km}$, potentially less if its dip is closer to $60^{\circ}$. A constant value of $h^{*} \sim 6 \mathrm{~km}$ for both types of faults could account for ratios $W_{A H} / h^{*} \sim 1.2$ and $W_{D F} / h^{*} \sim 1.7$, which could explain the greater coupling coefficient of detachment faults solely in terms of greater fault surface, and indirectly in terms of the colder thermal regime of detachment sections [Escartín et al., 2008a]. Expected values of $h^{*}$ based on experimental data are, however, typically much lower than $\sim 1 \mathrm{~km}$. Experimentally determined values for $b$ and $|a-b|$ are of order $10^{-2}$ and $10^{-3}$, respectively [e.g., Marone, 1998; He et al., 2007]. A reasonable estimate for $\sigma_{n}$ is $\sim 50 \mathrm{MPa}$, assuming that lithostatic pressure at a depth of a few kilometers is partially relieved by a hydrostatic pore fluid pressure. According to equation (18), a kilometer-scale $h^{*}$ therefore requires a value of $d_{C}$ of $\sim 1 \mathrm{~mm}$, which is at least an order of magnitude greater than values determined through laboratory experiments [e.g., Boettcher et al., 2007; He et al., 2007]. Several explanations have been put forward to explain this discrepancy; most notably that $d_{C}$ may increase under greater normal stress due to changes in the geometry of asperity contacts [Boettcher et al., 2007; Liu et al., 2012], or that the value of $d_{C}$ measured in laboratory samples with gouge thicknesses of $\sim 1 \mathrm{~mm}$ simply do not scale up to the thicker fault zones documented in the field.

To summarize, the fact that earthquakes account for a greater proportion of fault slip on detachment faults than on abyssal hill faults can be interpreted with two end-member models. In the first end-member, aseismic creep events and seismic ruptures are confined to different portions of the fault surface, and this segregation is controlled by strength heterogeneities most likely imparted by lithological (and possibly pore fluid pressure) variability. In the second end-member, the length scale of heterogeneities is small relative to the fault size, and the entire plane can rupture either seismically or aseismically in a homogeneous fashion. The greater contribution of seismic slip to detachment fault growth could thus simply reflect the greater surface of detachments relative to the characteristic nucleation size of earthquakes. The true explanation probably involves a combination of both end-members. A more detailed characterization of the modes of deformation recorded in the gouge of oceanic normal faults, as well as more extensive measurements of the frictional properties of basalt, gabbro, olivine, serpentine, and talc over a wide range of pressure and temperature conditions will be needed to move this discussion forward.

\section{Conclusions}

This study provides new insights into the seismogenic behavior of mid-ocean ridge normal faults by reporting correlations between earthquake statistics and the mode of seafloor accretion along the slow spreading MAR. In agreement with earlier studies [Escartín et al., 2008a; Simão et al., 2010], we find significantly greater seismicity rates within ridge sections that feature one or several large-offset detachment faults, compared to sections characterized by symmetric abyssal-hill type morphology. A simple declustering analysis supports the idea that this difference may originate in background seismicity rates and not from differences in the characteristics of mainshock-aftershock sequences across section type. We further investigate the state of seismic coupling across all sections by estimating seismic moment release rates using a methodology that minimizes the effect of our short measurement window (i.e., sensitivity to the greatest recorded earthquake). We generally find greater coupled thicknesses at DB sections (with a wider range of estimates), and establish that the distribution of coupled thicknesses in DB sections is likely distinct from that of $A B$ sections within $95 \%$ confidence.

The state of seismic coupling in DB sections is consistent with a coupled thickness that is greatest within a few detachment fault systems of limited along-axis extent, and moderate within the rest of the section. This idea is supported by the independent estimate of a $\sim 2000 \mathrm{~m}$ coupled thickness at the TAG detachment fault [DeMartin, 2007], which is greater than at most other sections studied here. We thus propose that, to first-order along slow spreading ridges, detachment faults are characterized by the greatest coupled thickness $(\sim 2000 \mathrm{~m})$, while abyssal hill bearing seafloor is characterized by a moderate coupled thickness of $\sim 500 \mathrm{~m}$.

This factor of 4 difference can be interpreted in multiple ways. Coupled thickness could represent the true extent of a fully coupled portion of the fault where slip only occurs seismically, while only aseismic slow creep can occur on the rest of the fault. In this framework, the difference between detachment and abyssal hill faults could reflect differences in the distribution of lithological heterogeneities in the fault zones. 
However, OBS surveys indicate that micro-earthquakes can take place over wide areas of both abyssal hill and detachment faults. Thus, an alternative explanation for coupled thickness is that it represents a mixed mode of fault growth oscillating between episodes of creep and seismic ruptures on the entire fault [e.g., Liu et al., 2012]. If that is the case, then a sizeable proportion of the cumulative slip can be assumed to be aseismic, regardless of fault type. Episodes of aseismic slip on oceanic normal faults may resemble shallow slow slip events recently documented on the Hikurangi subduction zone interface [Wallace et al., 2016]. We estimate that if magmatic processes play no role in loading faults in between eruptions (Scenario $A$ in section 5.3), about $10 \%$ of fault slip may occur seismically on abyssal hill faults and $\sim 40 \%$ on detachment faults. These estimates shift to $\sim 30$ and $\sim 60 \%$ under the other end-member scenario (Scenario B), where fault loading reflects the full long-term magmatic strain even on short time scales. In any case, a factor of 24 difference subsists between the seismic coupling coefficient of abyssal hill and detachment faults.

Recent numerical models of seismic cycles on transform and thrust faults based on rate and state friction theory argue that mixed-modes of fault slip may be favored when the characteristic nucleation size of frictional instabilities is comparable to the extent of the seismogenic zone [Liu et al., 2012]. In this framework, the difference between detachment and abyssal hill fault coupling could be fully explained by differences in the extent of the area prone to frictional instabilities, which may in turn reflect differences in thermal regime stemming from differences in the time-averaged melt supply. This model has the advantage of requiring no ad hoc frictional heterogeneities in the fault plane. Its main limitation is that a km-scale earthquake nucleation size appears incompatible with current laboratory estimates of the rate-and-state friction parameter $d_{C}$. This arguably illustrates the difficulty of extrapolating lab-scale measurements to the scale of lithospheric fault systems. Alternatively, the mixed modes of fault slip at detachment versus abyssal hill faults may be controlled by the dynamic frictional properties of their respective mineral assemblages (which are to date not well characterized), as well as by the characteristic length scales of lithological heterogeneities in the fault zone.

Regardless of the microscopic and mechanistic interpretation that is most appropriate for seismic coupling, our study makes predictions regarding ridge seismicity that are testable with future deployments of $10 \mathrm{~km}$ scale OBS arrays. Specifically, we propose that elevated rates of seismic moment release (and therefore coupled thickness) could be a signature of active detachment faulting. A higher resolution characterization of seismicity along axis, coupled with detailed studies of seafloor geology will be needed to test these ideas. Finally, a straightforward next step will be to apply the concepts introduced here to the systematic variations in seismic coupling across all spreading rates.

Acknowledgments

The authors wish to thank Thorsten Becker, Del Bohnenstiehl and two anonymous reviewers for their detailed and helpful comments. We also acknowledge Mark Behn, Yajing Liu, Maya Tolstoy, Hannah Mark, Heather Savage, Mathilde Cannat, and Roger Buck for useful discussions. This work was supported by an LDEO Postdoctoral Fellowship (J.-A.O.) and through CNRS (J.E.). The seismicity catalogs analyzed here are available as Supporting Information, along with scripts to estimate Gutenberg-Richter parameters and moment release rates.

\section{References}

Aki, K. (1965), Maximum likelihood estimate of b in the formula $\log \mathrm{N}=\mathrm{a}-\mathrm{bM}$ and its confidence limits, Bull. Earthquake Res. Inst. Tokyo Univ., 43, 237-239.

Barclay, A. H., D. R. Toomey, and S. C. Solomon (2001), Microearthquake characteristics and crustal $\mathrm{V}_{\mathrm{P}} / \mathrm{V}_{\mathrm{S}}$ structure at the Mid-Atlantic Ridge, $35^{\circ}$ N, J. Geophys. Res., 106, 2017-2034.

Behn, M. D., and G. Ito (2008), Magmatic and tectonic extension at mid-ocean ridges: 1. Controls on fault characteristics, Geochem. Geophys. Geosyst., 9, Q08O10, doi:10.1029/2008GC001965.

Bird, P., Y. Y. Kagan, and D. D. Jackson (2002), Plate tectonics and earthquake potential of spreading ridges and oceanic transform faults, in Plate Boundary Zones, Geodyn. Ser., vol. 30, pp. 203-218, edited by S. Stein and J. T. Freymueller, pp. 203-218, AGU, Washington, D. C.

Boettcher, M., G. Hirth, and B. Evans (2007), Olivine friction at the base of oceanic seismogenic zones, J. Geophys. Res., 112, B01205, doi: $10.1029 / 2006 J$ J004301.

Bohnenstiehl, D. R., and M. Tolstoy (2003), Comparison of teleseismic- and hydroacoustic-derived earthquake locations along the NorthCentral Mid-Atlantic Ridge and Equatorial East Pacific Rise, Seismol. Res. Lett., 74(6), 790-810.

Bohnenstiehl, D. R., M. Tolstoy, D. K. Smith, and C. G. Fox (2000), Earthquake sequences detected using autonomous underwater hydrophone data from the northern Mid-Atlantic Ridge: February 1999-February 2000, Eos Trans. AGU, 81(48), Fall Meet. Suppl., Abstract T51D-13.

Bohnenstiehl, D. R., M. Tolstoy, R. P. Dziak, C. G. Fox, and D. K. Smith (2002), Aftershock sequences in the mid-ocean ridge environment: An analysis using hydroacoustic data, Tectonophysics, 354, 49-70.

Buck, W. R. (1988), Flexural rotation of normal faults, Tectonics, 7, 959-973, doi:10.1029/TC007i005p00959.

Buck, W. R., L. L. Lavier, and A. N. B. Poliakov (2005), Modes of faulting at mid-ocean ridges, Nature, 434, 719-723.

Cannat, M., C. Mével, M. Maia, C. Deplus, C. Durand, P. Gente, P. Agrinier, A. Belarouchi, G. Dubuisson, E. Humler, and J. Reynolds (1995), Thin crust, ultramafic exposures, and rugged faulting patterns at the Mid-Atlantic Ridge $\left(22^{\circ}-24^{\circ} \mathrm{N}\right)$, Geology, $23,49-52$.

Cannat, M. (1996), How thick is the magmatic crust at slow spreading oceanic ridges?, J. Geophys. Res., 101, $2847-2857$.

Chernak, L., and G. Hirth (2010), Deformation of antigorite serpentinite at high temperature and pressure, Earth Planet. Sci. Lett., 296, 23-33.

Choi, E., and W. R. Buck (2012), Constraints on the strength of faults from the geometry of rider blocks in continental and oceanic core complexes, J. Geophys. Res., 117, B04410, doi:10.1029/2011JB008741. 
Cowie, P. A., C. H. Scholz, M. Edwards, and A. Malinverno (1993), Fault strain and seismic coupling on mid-ocean ridges, J. Geophys. Res., 98, $17,911-17,920$.

Crawford, W. C., A. Rai, S. C. Singh, M. Cannat, J. Escartín, H. Wang, R. Daniel, and V. Combier (2013), Hydrothermal seismicity beneath the summit of Lucky Strike volcano, Mid-Atlantic Ridge, Earth Planet. Sci. Lett., 373, 118-128.

Das, R., H. R. Wason, and M. L. Sharma (2011), Global regression relations for conversion of surface wave and body wave magnitudes to moment magnitude, Nat. Hazards, 59, 801-810.

Davis, S. D., and C. Frohlich (1991), Single-link cluster analysis, synthetic earthquake catalogues, and aftershock identification, Geophys. J. Int., 104, 289-306.

DeMartin, B. J. (2007), Experimental and seismological constraints on the rheology, evolution, and alteration of the lithosphere at oceanic spreading centers, PhD thesis, MIT-WHOI Joint Prog in Oceanogr., Cambridge, Mass.

DeMartin, B. J., R. A. Sohn, J. P. Canales, and S. E. Humphris (2007), Kinematics and geometry of active detachment faulting beneath the Trans-Atlantic Geotraverse (TAG) hydrothermal field on the Mid-Atlantic Ridge, Geology, 35, 711-714, doi:10.1130/G23718A.1.

Dick, H. J. B., Tivey, M. A., and B. E., Tucholke (2008), Plutonic foundation of a slow-spreading ridge segment: Oceanic core complex at Kane Megamullion, $23^{\circ} 30^{\prime} \mathrm{N}, 45^{\circ} 20^{\prime} \mathrm{W}$, Geochem. Geophys. Geosyst., 9(5).

Dieterich, J. H. (1979), Modeling of rock friction: 1. Experimental results and constitutive equations, J. Geophys. Res., 84, 2161-2168, doi: $10.1029 / J B 084$ iB05p02161.

Dziak R. P., S. R. Hammond, and C. G. Fox (2011), A 20-year hydroacoustic time series of seismic and volcanic events in the Northeast Pacific Ocean, Oceanography, 24(3), 280-293.

Dziak, R. P., D. K. Smith, D. R. Bohnenstiehl, C. Fox, D. Desbruyères, H. Matsumoto, M. Tolstoy, and D. J. Fornari (2004), Evidence of a recent magma dike intrusion at the slow spreading Lucky Strike segment, Mid-Atlantic Ridge, J. Geophys. Res., 109, B12102, doi:10.1029/ $2004 J B 003141$.

Escartín, J., G. Hirth, and B. Evans (1997), Effects of serpentinization on the lithospheric strength and the style of normal faulting at slowspreading ridges, Earth Planet. Sci. Lett., 151(3-4), 181-189, doi:10.1016/S0012-821X(97)81847-X.

Escartín, J., P. A. Cowie, R. C. Searle, S. Allerton, N. C. Mitchell, C. J. MacLeod, and A. P. Slootweg (1999), Quantifying tectonic strain and magmatic accretion at a slow spreading ridge segment, Mid-Atlantic Ridge, 29N, J. Geophys. Res., 104, 10,424-10,437.

Escartín, J., C. Mével, C. J. MacLeod, and A. M. McCaig (2003), Constraints on deformation conditions and the origin of oceanic detachments: The Mid-Atlantic Ridge core complex at 15²5'N, Geochem. Geophys. Geosyst., 4(8), 1067, doi:10.1029/ 2001 GC000278.

Escartín, J., D. K. Smith, J. Cann, H. Schouten, C. H. Langmuir, and S. Escrig (2008a), Central role of detachment faults in accretion of slowspreading oceanic lithosphere, Nature, 455, 790-794, doi:10.1038/nature07333.

Escartín, J., M. Andreani, G. Hirth, and B. Evans (2008b), Relationships between the microstructural evolution and the rheology of talc at elevated pressures and temperatures, Earth Planet. Sci. Lett., 268, 463-475.

Fialko, Y. A., and A. M. Rubin (1998), Thermodynamics of lateral dike propagation: Implications for crustal accretion at slow-spreading ridges, J. Geophys. Res., 103(B2), 2501-2514

Frohlich, C. (2007), Practical suggestions for assessing rates of seismic moment release, Bull. Seismol. Soc. Am., 97, $1158-1166$.

Frohlich, C., and L. R. Wetzel (2007), Comparison of seismic moment release rates along different types of plate boundaries, Geophys. J. Int., $171,909-920$.

Grevemeyer, I., T. J. Reston, and S. Moeller (2013), Microseismicity of the Mid-Atlantic Ridge at $7^{\circ} \mathrm{S}-8^{\circ} 15^{\prime} \mathrm{S}$ and at the Logatchev Massif oceanic core complex at $14^{\circ} 40^{\prime} \mathrm{N}-14^{\circ} 50^{\prime} \mathrm{N}$, Geochem. Geophys. Geosyst., 14, 3532-3554, doi:10.1002/ggge.20197.

Hansen, L. N., M. Cheadle, B. John, H. J. B. Dick, B. E. Tucholke, and M. Tivey (2013), Mylonitic deformation at the Kane Oceanic Core Complex: Implications for the rheological characteristics of oceanic detachment faults, Geochem. Geophys. Geosyst., 14, 3085-3108, doi: 10.1002 /ggge.20184.

Haymon, R. M., et al. (1993), Volcanic eruption of the mid-ocean ridge along the east pacific rise crest at $9^{\circ} 45-52^{\prime} \mathrm{N}$ : Direct submersible observations of seafloor phenomena associated with an eruption event in April, 1991, Earth Planet. Sci. Lett., 119(1), 85-101.

He, C., Z. Wang, and W. Yao (2007), Frictional sliding of gabbro gouge under hydrothermal conditions, Tectonophysics, 445, 353-362.

Hirth, G., J. Escartín, and J. Lin (1998), The rheology of the lower oceanic crust: Implications for lithospheric deformation at mid-ocean ridges, in Faulting and Magmatism at Mid-Ocean Ridges, Geophys. Monogr. Ser., vol. 106, edited by W. R. Buck et al., pp. 291-303, AGU, Washington, D. C., doi:10.1029/GM106p0291.

Huang, P. Y., and S. C. Solomon (1988), Centroid depths of mid-ocean ridge earthquakes: dependence on spreading rate, J. Geophys. Res., $93,13,445-13,447$.

Huang, P. Y., S. C. Solomon, E. A. Bergman, and J. L. Nabelek (1986), Focal depths and mechanisms of Mid-Atlantic Ridge earthquakes from body waveform inversion, J. Geophys. Res., 91, 579-596.

Ildefonse, B., D. K. Blackman, B. E. John, Y. Ohara, D. J. Miller, C. J. MacLeod, and Integrated Ocean Drilling Program Expeditions 304/305 Science Party (2007), Oceanic core complexes and crustal accretion at slow-spreading ridges, Geology, 35(7), 623-626.

International Seismological Centre (2013), On-line bulletin, Int. Seismol. Cent., Thatcham, U. K. [Available at http://www.isc.ac.uk]

Ito, G., and M. D. Behn (2008), Magmatic and tectonic extension at mid-ocean ridges: 2. Origin of axial morphology, Geochem. Geophys. Geosyst., 9, Q08010, doi:10.1029/2008GC001970.

Kagan, Y. Y. (1997), Seismic moment-frequency relation for shallow earthquakes: Regional comparisons, J. Geophys. Res., 102, 2835-2852.

Karson, J. A., G. L. Früh-Green, D. S. Kelley, E. A. Williams, D. R. Yoerger, and M. Jakuba (2006), Detachment shear zone of the Atlantis Massif core complex, Mid-Atlantic Ridge, 30N, Geochem. Geophys. Geosyst., 7, Q06016, doi:10.1029/2005GC001109.

Kong, L. S. L., S. C. Solomon, and G. M. Purdy (1992), Micro-earthquake characteristics of a Mid-Ocean Ridge along-axis high, J. Geophys. Res., 97, 1659-1685.

Kuo, B.-Y., and D. W. Forsyth (1988), Gravity anomalies of the ridge-transform system in the South Atlantic between 31 and $34.5^{\circ} \mathrm{S}$ : Upwelling centers and variations in crustal thickness, Mar. Geophys. Res., 10, 205-232.

Lavier, L. L., Buck, W. R., and A. N. B. Poliakov (1999), Self-consistent rolling-hinge model for the evolution of large-offset low-angle faults, Geology, 27(12), 1127-1130, doi:10.1130/0091-7613(1999)027<1127:SCRHMF>2.3.CO;2.

Liu, Y., J. J. McGuire, and M. D. Behn (2012), Frictional behavior of oceanic transform faults and its influence on earthquake characteristics, J. Geophys. Res., 117, B04315, doi:10.1029/2011JB009025.

Macdonald, K. C., P. J. Fox, R. T. Alexander, R. Pockalny, and P. Gente (1996), Volcanic growth faults and the origin of Pacific abyssal hills, Nature, 380, 125-129.

Mackwell, S. J., M. E. Zimmerman, and D.L. Kohlstedt (1998), High-temperature deformation of dry diabase with application to tectonics on Venus, J. Geophys. Res., 103, 975-984. 
MacLeod, C. J., R. C. Searle, B. J. Murton, J. F. Casey, C. Mallows, S. C. Unsworth, K. L. Achenbach, and M. Harris (2009), Life cycle of oceanic core complexes, Earth Planet. Sci. Lett., 287, 333-344.

MacLeod, C. J., J. Carlut, J., Escartin, H. Horen, H., and A. Morris (2011), Quantitative constraint on footwall rotations at the $15^{\circ} 45^{\prime} \mathrm{N}$ oceanic core complex, Mid-Atlantic Ridge: Implications for oceanic detachment fault processes, Geochem. Geophys. Geosyst., 12, Q0AG03, doi: $10.1029 / 2011 \mathrm{GC} 003503$.

Marone, C. (1998), Laboratory-derived friction laws and their application to seismic faulting, Annu. Rev. Earth Planet. Sci., 26, 643-696.

McCaig, A. M., R. A. Cliff, J., Escartin, A. E., Fallick, and C. J. MacLeod (2007), Oceanic detachment faults focus very large volumes of black smoker fluids, Geology, 35, 935-938, doi:10.1130/G23657A.1.

McGuire, J., J. Collins, P. Gouédard, E. Roland, D. Lizarralde, M. S. Boettcher, M. D. Behn, and R. van der Hilst (2012), Variations in earthquake rupture properties along the Gofar transform fault, East Pacific Rise, Nature, 5, 336-341.

Mitchell, E. K., Y. Fialko, and K. M. Brown (2015), Frictional properties of gabbro at conditions corresponding to slow slip events in subduction zones, Geochem. Geophys. Geosyst., 16, 4006-4020, doi:10.1002/2015GC006093.

Moore, D. E., and D. A. Lockner (2011), Frictional strengths of talc-serpentine and talc-quartz mixtures, J. Geophys. Res., 116, B01403, doi: 10.1029/2010JB007881.

Moore, D. E., D. A. Lockner, S. Ma, R. Summers, and J. D. Byerlee (1997), Strengths of serpentinite gouges at elevated temperatures, J. Geophys. Res., 102, 14,787-14,801, doi:10.1029/97JB00995.

Morris, A., J. S. Gee, N. Pressling, B. E. John, C. J. MacLeod, C. B. Grimes, and R. C. Searle (2009), Footwall rotation in an oceanic core complex quantified using reoriented Integrated Ocean Drilling Program core samples, Earth Planet. Sci. Lett., 287, 217-228.

Nooner, S. L., L. Bennati, E. Calais, W. R. Buck, I. J. Hamling, T. J. Wright, and E. Lewi (2009), Post-rifting relaxation in the Afar region, Ethiopia, Geophys. Res. Lett., 36, L21308, doi:10.1029/2009GL040502.

Olive, J.-A., M. D. Behn, and B. E. Tucholke (2010), The structure of oceanic core complexes controlled by the depth distribution of magma emplacement, Nat. Geosci., 3, 491-495, doi:10.1038/NGEO888.

Olive, J.-A., M. D. Behn, G. Ito, W. R. Buck, J. Escartín, and S. Howell (2015), Sensitivity of seafloor bathymetry to climate-driven fluctuations in mid-ocean ridge magma supply, Science, 350, 310-313, doi:10.1126/science.aad0715.

Pan, J., and A. M. Dziewonski (2005), Comparison of mid-oceanic earthquake epicentral differences of travel time, centroid locations, and those determined by autonomous underwater hydrophone arrays, J. Geophys. Res., 110, B07302, doi:10.1029/2003JB002785.

Paulatto, M., Canales, J. P., Dunn, R. A., and R. A. Sohn (2015), Heterogeneous and asymmetric crustal accretion: New constraints from multibeam bathymetry and potential field data from the Rainbow area of the Mid-Atlantic Ridge $\left(36^{\circ} 15^{\prime} \mathrm{N}\right)$, Geochem. Geophys. Geosyst., 16 , 2994-3014, doi:10.1002/2015GC005743.

Picazo, S., M. Cannat, A. Delacour, J. Escartín, S. Rouméjon, and S. Silantyev (2012), Deformation associated with the denudation of mantlederived rocks at the Mid-Atlantic Ridge $13^{\circ}-15^{\circ} \mathrm{N}$ : The role of magmatic injections and hydrothermal alteration, Geochem. Geophys. Geosyst., 13, Q04G09, doi:10.1029/2012GC004121.

Qin, R., and W. R. Buck (2008), Why meter-wide dikes at oceanic spreading centers?, Earth Planet. Sci. Lett., 265, 466-474.

Reinen, L. A., J. D. Weeks, and T. E. Tullis (1991), The frictional behavior of serpentinite: Implications for aseismic creep on shallow crustal faults, Geophys. Res. Lett., 18, 1921-1924.

Reston, T., and C. R. Ranero (2011), The 3-D geometry of detachment faulting at mid-ocean ridges, Geochem. Geophys. Geosyst., 12 Q0AG05, doi:10.1029/2011GC003666.

Rice, J. R., and A. L. Ruina (1983), Stability of steady frictional slipping, J. Appl. Mech., 50(2), 343-349.

Rubin, A. M., and J.-P. Ampuero (2005), Earthquake nucleation on (aging) rate and state faults, J. Geophys. Res., 110, B11312, doi:10.1029/ $2005 J B 003686$.

Ruina, A. L. (1983), Slip instability and state variable friction laws, J. Geophys. Res., 88, 10,359-10,370.

Rundquist, D. V., and P. O. Sobolev (2002), Seismicity of mid-oceanic ridges and its geodynamic implications: A review, Earth Sci. Rev., 58, $143-161$.

Ryan, W. B. F., et al. (2009), Global multi-resolution topography synthesis, Geochem. Geophys. Geosyst., 10, Q03014, doi:10.1029/ $2008 \mathrm{GC} 002332$.

Schlindwein, V. (2012), Teleseismic earthquake swarms at ultraslow spreading ridges: Indicator for dyke intrusions?, Geophys. J. Int., 190 $442-456$.

Scholz, C. H. (1998), Earthquakes and friction laws, Nature, 391, 37-42, doi:10.1038/34097.

Schorlemmer, D., S. Wiemer, and M. Wyss (2005), Variations in earthquake-size distribution across different stress regimes, Nature, 437, 539-542.

Schouten, H., D. K. Smith, J. R. Cann, and J. Escartin (2010), Tectonic versus magmatic extension in the presence of core complexes at slowspreading ridges from a visualization of faulted seafloor topography, Geology, 38(7), 615-618.

Schroeder, T., and B. E. John (2004), Strain localization on an oceanic detachment fault system, Atlantis Massif, $30^{\circ} \mathrm{N}$, Mid-Atlantic Ridge Geochem. Geophys. Geosyst., 5, Q11007, doi:10.1029/2004GC000728.

Searle, R. C., and A. S. Laughton (1977), Sonar studies of the Mid-Atlantic Ridge and Kurchatov Fracture Zone, J. Geophys. Res., 82, 53135328.

Simão, N., J. Escartín, J. Goslin, J. Haxel, M. Cannat, and R. Dziak (2010), Regional seismicity of the Mid-Atlantic Ridge: Observations from autonomous hydrophone arrays, Geophys. J. Int., 183, 1559-1578.

Sinton, J. M., and R. S. Detrick (1992), Mid-ocean ridge magma chambers, J. Geophys. Res., 97, 197-216, doi:10.1029/91JB02508.

Smith, D. K., M. Tolstoy, C. G. Fox, D. R. Bohnenstiehl, H. Matsumoto, and M. J. Fowler (2002), Hydroacoustic monitoring of seismicity at the slow-spreading Mid-Atlantic Ridge, Geophys. Res. Lett., 29(11), 1518, doi:10.1029/2001GL013912.

Smith, D. K., J. Escartín, M. Cannat, M. Tolstoy, C. G. Fox, D. R. Bohnenstiehl, and S. Bazin (2003), Spatial and temporal distribution of seismicity along the northern Mid-Atlantic Ridge ( $\left(15^{\circ}-35^{\circ} \mathrm{N}\right)$, J. Geophys. Res., 108(B3), 2167, doi:10.1029/2002JB001964.

Smith, D. K., Cann, J., and J. Escartín (2006), Widespread active detachment faulting and core complex formation near $13^{\circ} \mathrm{N}$ on the MidAtlantic Ridge, Nature, 442, 440-443, doi:10.1038/nature04950.

Sobolev, P. O., and D. V. Rundquist (1999), Seismicity of oceanic and continental rifts-A geodynamic approach, Phys. Earth Planet. Int., 111, 253-266.

Solomon, S. C., P. Y. Huang, and L. Meinke (1988), The seismic moment budget of slowly spreading ridges, Nature, 334, 58-60.

Spencer. S., D. K. Smith, J. R. Cann, J. Lin, and E. MacAllister (1997), Structure and stability of non-transform discontinuities on the MidAtlantic Ridge between $24^{\circ} \mathrm{N}$ and $30^{\circ} \mathrm{N}$, Mar. Geophys. Res., 19, 339-362.

Storchak, D. A., D. Di Giacomo, I. Bondár, E. R. Engdahl, J. Harris, W. H. K. Lee, A. Villasenõr, and P. Bormann (2013), Public release of the ISCGEM Global Instrumental Earthquake Catalogue (1900-2009), Seismol. Res. Lett., 84, 810-815. 
Thatcher, W., and D. P. Hill (1995), A simple model for the fault-generated morphology of slow-spreading mid-oceanic ridges, J. Geophys. Res., 100, 561-570, doi:10.1029/94JB02593.

Tolstoy, M., D. R. Bohnenstiehl, M. H. Edwards, and G. J. Kurras (2001), Seismic character of volcanic activity at the ultraslow-spreading Gakkel Ridge, Geology, 29, 726-729.

Toomey, D. R., S. C. Solomon, and G. M. Purdy (1988), Microearthquakes beneath Median Valley of Mid-Atlantic Ridge near $23^{\circ}$ N: Tomography and tectonics, J. Geophys. Res., 93, 9093-9112.

Tucholke, B. E., and J. Lin (1994), A geological model for the structure of ridge segments in slow spreading ocean crust, J. Geophys. Res., 99, 11,937-11,958.

Tucholke, B. E., J. Lin, M. C. Kleinrock, M. A. Tivey, T. B. Reed, J. Goff, and G.E. Jaroslow (1997), Segmentation and crustal structure of the western Mid-Atlantic Ridge flank, $25^{\circ} 25^{\prime}-27^{\circ} 10^{\prime} \mathrm{N}$ and 0-29 m.y., J. Geophys. Res., 102, 10,203-10,223.

Tucholke, B. E., M. D. Behn, W. R. Buck, and J. Lin (2008), Role of melt supply in oceanic detachment faulting and formation of megamullions, Geology, 36, 455-458.

Violay, M., G. Di Toro, B. Gibert, S. Nielsen, E. Spagnuolo, P. Del Gaudio, P. Azais, and P. G. Scarlato (2014), Effect of glass on the frictional behavior of basalts at seismic slip rates, Geophys. Res. Lett., 41, 384-355, doi:10.1002/2013GL058601.

Wallace, L. M., S. C. Webb, Y. Ito, K. Mochizuki, R. Hino, S. Henrys, S. Y. Schwartz, and A. F. Sheehan (2016), Slow slip near the trench at the Hikurangi subduction zone, New Zealand, Science, 353(6286), 701-704.

Wiemer, S., and M. Wyss (2000), Minimum magnitude of completeness in earthquake catalogs: Examples from Alaska, the Western United States, and Japan, Bull. Seismol. Soc. Am., 90(4), 859-869.

Wilcock, W. S. D., S. C. Solomon, G. M. Purdy, and D. R. Toomey (1992), Microearthquakes on and near the East Pacific Rise, $9^{\circ}-10^{\circ} \mathrm{N}, \mathrm{Geo}^{-}$ phys. Res. Lett., 19, 2131-2134.

Wilcock, W. S. D., E. E. Hooft, D. R. Toomey, P. R. McGill, A. H. Barclay, D. S. Stakes, and T. M. Ramirez (2009), The role of magma injection in localizing black-smoker activity, Nat. Geosci., 2, 509-513.

Wilson, S. C., B. J. Murton, and R. N. Taylor (2013), Mantle composition controls the development of an oceanic core complex, Geochem. Geophys. Geosyst., 14, 979-995, doi:10.1002/ggge.20046.

Wolfe, C. J., G. M. Purdy, D. R. Toomey, and S. C. Solomon (1995), Microearthquake characteristics and crustal velocity structure at $29^{\circ} \mathrm{N}$ on the Mid-Atlantic Ridge: The architecture of a slow spreading segment, J. Geophys. Res., 100, 24,449-24,472. 